\title{
1 Prawn aquaculture as a method for schistosomiasis control and poverty 2 alleviation: a win-win approach to address a critical infectious disease of 3 poverty
}

6 Christopher M. Hoover ${ }^{1}$, Susanne H. Sokolow ${ }^{2,3}$, Jonas Kemp ${ }^{4 \dagger}$, James N. Sanchirico ${ }^{5}$, Andrea J.

7 Lund $^{6}$, Isabel Jones ${ }^{2}$, Tyler Higginson ${ }^{7}$, Gilles Riveau ${ }^{8}$, Amit Savaya-Alkalay ${ }^{9}$, Shawn Coyle ${ }^{10}$,

8 Chelsea L. Wood ${ }^{11}$, Fiorenza Micheli ${ }^{2}$, Renato Casagrandi ${ }^{12}$, Lorenzo Mari ${ }^{12}$, Marino Gatto ${ }^{12}$,

9 Andrea Rinaldo ${ }^{13}$, Javier Perez-Saez ${ }^{13}$, Jason R. Rohr ${ }^{14,15}$, Amir Sagi ${ }^{9}$, Justin V. Remais ${ }^{1, \S}$, Giulio

10 A. De Leo $^{2,3, \&, *}$

$12{ }^{1}$ Division of Environmental Health Sciences, University of California, Berkeley School of Public

13 Health, Berkeley, CA 94720 USA

$14{ }^{2}$ Department of Biology, Hopkins Marine Station, Stanford University, Pacific Grove, CA 93950 15 USA

$16 \quad{ }^{3}$ Woods Institute for the Environment and Center for Innovation in Global Health, Stanford

17 University, Stanford, CA 94305 USA

$18{ }^{4}$ Program in Human Biology, Stanford University, Stanford, CA 94305 USA

$19{ }^{5}$ Department of Environmental Science and Policy, University of California, Davis, Davis, CA

2095616 USA

$21{ }^{6}$ Emmett Interdisciplinary Program in Environment and Resources, School of Earth, Energy and

22 Environmental Sciences, Stanford University, Stanford, CA 94305 USA

$23{ }^{7}$ Middlebury Institute of International Studies at Monterey, Monterey, CA 93940 USA

$24 \quad{ }^{8}$ Biomedical Research Center EPLS, Saint Louis, Senegal

$25{ }^{9}$ Department of Life Sciences and the National Institute for Biotechnology in the Negev, Ben

26 Gurion University of the Negev, Beer Sheva, Israel.

$27{ }^{10}$ Kentucky State University, Aquaculture Division, Aquaculture Research Center, Frankfort, KY 2840601 USA.

$29{ }^{11}$ University of Washington, School of Aquatic and Fishery Sciences, Seattle, WA 98195 USA.

$30 \quad{ }^{12}$ Dipartimento di Elettronica, Informazione e Bioingegneria, Politecnico di Milano, 20133

31 Milano, Italy

$32{ }^{13}$ Laboratory of Ecohydrology, School of Architecture, Civil and Environmental Engineering,

33 Ecole Polytechnique Fédérale de Lausanne, CH-1015 Switzerland

$34{ }^{14}$ Department of Biological Sciences, University of Notre Damea, Notre Dame, IN, 46556 USA

$35{ }^{15}$ Department of Integrative Biology, University of South Florida, Tampa, FL, 33620 USA

36 Now at Google Brain

$37 \quad$ * Corresponding author

$38 \quad \S$ Denotes shared senior authorship 


\section{Abstract}

41 Recent evidence suggests crustacean snail predators may aid schistosomiasis control

42 programs by targeting the environmental component of the parasite's life cycle through

43 predation of the snail species that serve as intermediate hosts of the parasite. We evaluate

44 costs, benefits, and potential synergies between schistosomiasis control and aquaculture of

45 giant prawns using an integrated bio-economic-epidemiologic model. We identified

46 combinations of stocking density and aquaculture cycle length that maximize profit and offer

47 disease control benefits for sustainable schistosomiasis control. We consider two prawn

48 species in sub-Saharan Africa: the endemic, non-domesticated Macrobrachium vollenhovenii,

49 and the non-native, domesticated Macrobrachium rosenbergii. We find that, at profit-optimal

50 densities, both M. rosenbergii and M. vollenhovenii can complement conventional control

51 approaches (mass drug treatment of people) and lead to sustainable schistosomiasis control.

52 We conclude that integrated aquaculture strategies can be a win-win strategy in terms of

53 health and sustainable development in schistosomiasis endemic regions of the world. 


\section{$54 \quad$ Main}

55 Schistosomiasis is a debilitating disease of poverty, affecting around 200 million people

56 worldwide ${ }^{1,2}$. It is caused by trematode parasites of the genus Schistosoma that undergo a life

57 cycle involving passage between definitive human hosts and freshwater snails that act as

58 intermediate hosts. While safe and effective treatments, such as the anthelmintic drug

59 Praziquantel, are available to reduce parasite burden and associated symptoms from infected

60 individuals, rapid reinfection in highly endemic areas leads to persistent hotspots of

61 infection ${ }^{3,4}$. Successful long-term elimination efforts may require strategies that go beyond

62 conventional mass drug administration (MDA) campaigns to explicitly target the

63 environmental reservoir of the disease 5.

64 One option for reducing transmission is cultivating snail predators, such as river prawns,

65 via aquaculture. River prawns have been shown to reduce schistosomiasis transmission by

66 consuming snails in the aquatic environment where people contact infested water ${ }^{14,15}$. Given

67 that schistosomiasis is a disease of poverty, combining the nutritional and economic benefits

68 of prawn aquaculture with disease control via prawn predation on snails may offer a

69 sustainable approach to combat schistosomiasis and improve well-being and economic

70 development in endemic areas. Here, we develop an integrated bio-economic-epidemiologic

71 model to investigate whether extensive prawn aquaculture (using either endemic $M$.

72 vollenhovenii or nonbreeding monosex aquaculture of $M$. rosenbergii) can be managed at

73 schistosome transmission sites such as rice paddies or enclosed points of water contact

74 where people are exposed 15 to simultaneously maximize profit and control schistosomiasis.

75 There is a rich history of environmental interventions for schistosomiasis that target the

76 intermediate snail hosts ${ }^{6}$. Molluscicides are effective in reducing snail populations and have

77 been used in integrated campaigns to control schistosomiasis in areas of South America,

78 Northern Africa, and Southeast Asia ${ }^{6-8}$. However, these approaches generally require 
79 repeated applications of chemicals that may negatively affect non-target species in addition

80 to Schistosoma-bearing snails 9,10. A more sustainable approach for snail control involves the

81 introduction of snail predators, such as river prawns, which have been shown to actively seek

82 out and consume important intermediate hosts for human schistosomes in laboratory

83 settings, including Biomphalaria and Bulinus snails ${ }^{11-13}$. Field trials in which crustacean

84 predators have been introduced to reduce schistosomiasis transmission have been successful

85 in reducing reinfection rates in humans following MDA 14,15.

86 In addition to being voracious predators of snails 13,16 , river prawns are a valuable food

87 commodity ${ }^{17,18}$. The giant freshwater prawn Macrobrachium rosenbergii has been

88 domesticated and widely used in commercial hatchery-based aquaculture ${ }^{19}$, providing both

89 a key source of protein and encouraging local economic development 20. Furthermore,

90 advances in the production of nonbreeding $M$. rosenbergii monosex populations reduces the

91 risk of prawn invasion in areas this species is not native, suggesting safe use of this biological

92 control agent globally 21,22 . In sub-Saharan Africa, where at least $90 \%$ of schistosomiasis cases

93 occur ${ }^{1,23}$, the native African river prawn M. vollenhovenii has been proposed as an alternative

94 to M. rosenbergii for aquaculture ${ }^{21}$. Research into scalable M. vollenhovenii aquaculture is

95 ongoing, as the use of this native species may be more attractive due to its historical presence

96 in the local river ecology in western Africa.

97 Extensive prawn aquaculture, increasingly common in developing countries 17-19,

98 consists of large enclosures, low prawn densities, and no use of supplemental feed, substrate,

99 or additional oxygenation. As such, extensive aquaculture is more compatible with the water

100 resource management needs of rural communities in key areas of sub-Saharan Africa, and

101 can be easily integrated into rice agriculture that is increasingly an important part of food

102 production and is present in many schistosomiasis endemic areas ${ }^{24,25}$. 
103 Scaling the prawn aquaculture approach for schistosomiasis control requires that the

104 economic goals of prawn aquaculture are compatible with the public health goal of

105 schistosomiasis control. Thus, we seek to identify conditions under which schistosomiasis

106 reinfection in the human population may be curbed while maximizing the economic benefit

107 of prawn aquaculture. We first develop a bio-economic production model of Macrobrachium

108 spp. aquaculture to identify the stocking density and duration of the grow out phase that

109 maximizes profit for $M$. rosenbergii and M. vollenhovenii. Then, we expand an epidemiologic

110 model of schistosomiasis transmission dynamics to include snail size structure and infection

111 dynamics. This model is coupled with the aquaculture model through size- and density-

112 dependent prawn predation, and parameterized via results of previous laboratory and field-

113 based empirical studies. We use estimates of the disability adjusted life years (DALYs) lost

114 due to schistosomiasis infection derived from the integrated model to compare aquaculture-

115 based prawn interventions with conventional MDA interventions, and to estimate the

116 benefits of utilizing both MDA and prawn aquaculture for schistosomiasis control. We

117 conclude with an extensive sensitivity analysis to evaluate the feasibility of such

118 interventions in a variety of settings.

\section{Methods}

120 The integrated model has three components: a) a bio-economic aquaculture component,

121 simulating yields and accounting for density-dependent mortality and somatic growth of

122 Macrobrachium spp. prawns over a range of initial stocking densities; b) an epidemiologic

123 component to simulate the dynamics of mean schistosome worm burden in humans and

124 population and infection dynamics of intermediate-host snails through a size structured, SEI

125 compartmental model; and c) a predation function describing the rate at which prawns

126 consume snails as a function of snail density and of snail and prawn body sizes, which links

127 the epidemiologic and aquaculture models. 


\section{8 (a) Aquaculture model}

129 We assume that a necessary supply chain of hatcheries and nurseries supplies juvenile

130 prawns to stock at the desired transmission sites. The dynamics of a cohort of $P_{0}$ juvenile

131 prawns of initial mean length, $L_{0}[\mathrm{~mm}]$, stocked at time $t=0$ days in an enclosure of

$1321,000 \mathrm{~m}^{2}-$ a size consistent with either a large water contact site or a typical rice field in

133 small-scale, subsistence agriculture settings-are simulated over time as a function of

134 density-dependent and size-dependent growth and mortality.

135 Adult Macrobrachium rosenbergii males can be grouped in three different categories that

136 grow at different rates depending upon their body size and developmental phase: small males

137 (SM) between 5-20g, orange-clawed males (OC) between 30-180g, and blue-clawed male

138 (BC) reaching up to $250 \mathrm{~g}$, with growth of some smaller prawns being suppressed by the

139 largest BC males ${ }^{26}$. Though this same social structure has not been investigated for $M$.

140 volenhovenii, we assume here that it is the same. Growth of individual crustaceans is typically

141 stepwise and occurs through a sequence of molting events, but here the population-average

142 growth of prawns is modeled as somatic growth with the von Bertalanffy growth equation

143 (VBGE) ${ }^{27}$ :

$$
\frac{d L}{d t}=k^{*}\left(L_{\infty}-L\right)
$$

145 VBGE produces a classic increasing-and-saturating growth curve with length $L$ at time $t$ (days

146 after stocking) eventually approaching the mean asymptotic length, $L_{\infty}$. Based on

147 experimental stocking trials showing reduced growth rates of M. rosenbergii at high stocking

148 densities ${ }^{26}$, a modified Brody growth coefficient, $k^{*}$, was estimated as a decreasing function

149 of total population biomass, $\Omega$ :

$$
k^{*}(\Omega)=\frac{k_{\max }}{1+\gamma \Omega(t)}
$$


151 where $k_{\max }$ is the maximum value of the Brody coefficient at low densities and $\gamma$ a coefficient

152 parameterized to produce a density-dependent reduction in somatic growth qualitatively

153 resembling that observed in experimental trials ${ }^{26}$.

154 Total population biomass, $\Omega(t)$, is computed as the product of mean prawn body size in

155 grams, $B(t)$, and population size, $P(t)$, $t$ days after stocking:

$$
\Omega(t)=B(t) P(t)
$$

157 Body size $B(t)$ is derived as an allometric function of prawn length, $L(t)$, from $M$. rosenbergii

158 grow-out data 28,29 :

$$
B(t)=a_{P} L(t)^{b_{P}}
$$

160 As prawns are generalist consumers with a wide range of invertebrate fauna and organic

161 detritus in their diet ${ }^{30}$, growth as described by eq. 1-4 is assumed independent from snails'

162 density and the corresponding predation rates.

163 After stocking, the total number of prawns in the enclosure decreases over time, with per-

164 capita mortality rate modeled as an additive function of two components: (i) an exponentially

165 decreasing function of body size, $B(t)$, as large prawns exhibit lower mortality than small

166 prawns ${ }^{31}$; (ii) a linearly increasing function of total population biomass, $\Omega(t)$, which accounts

167 for density-dependent competition for resources and cannibalism at high population

168 densities ${ }^{26}$. Accordingly, the dynamics of a cohort of initial size $P_{0}$ was described as follows:

$$
\frac{d P}{d t}=-P\left(\mu_{P} B^{-d}+\omega \Omega\right)
$$

170 with parameters $\mu_{P}$ and $d$ derived from previous studies 31,32 and $\omega$ parameterized to

171 produce density-dependent mortality outcomes qualitatively similar to those observed in the

172 experimental trials by Ranjeet and Kurup ${ }^{26}$. Natural recruitment is excluded from the

173 aquaculture model, as new prawns enter the system only in discrete, exogenously controlled 
174 events, when $P_{0}$ prawns of initial average body size $L_{0}$ are stocked from nurseries and grown

175 out to market size. We assume natural, size- and density-dependent mortality are the only

176 causes of prawn population decline and do not consider other sources such as predation by

177 e.g. seabirds, escape from enclosures or rice fields, disease outbreaks, or declines in water

178 quality that may affect prawn health.

179 Prawns weighing $<30 \mathrm{~g}$ are generally not of commercial interest, therefore only OC and

180 BC males are considered marketable. Experimental trials by Ranjeet and Kurup with $M$.

181 rosenbergii 26 showed the fraction of retrievable, market-size ( $>30 \mathrm{~g})$ prawns decreases

182 linearly with increasing prawn stocking density. Accordingly, commercial yield at the end of

183 a production cycle of length $t=T$ is only a fraction of the total biomass:

$$
Y\left(T, P_{0}\right)=\zeta\left(P_{0}\right) \cdot \Omega(T)
$$

185 where $\zeta$, the fraction of marketable size prawns in the population, is a decreasing function of

186 initial stocking density $P_{0}$ estimated from data in the Ranjeet and Kurup experiments ${ }^{26}$.

187 Cumulative profits over a finite time horizon are determined by the profit produced per

188 cycle and the number of cycles completed within the given time period. In a time period of

$189 T_{\max }$ days, the number of aquaculture cycles completed for each Macrobrachium species (sp)

190 is $n^{s p}=\operatorname{round}\left(\frac{T_{\max }}{T}\right)$. Cumulative discounted profit for each species, $C P^{s p}$, is then estimated

191 as the sum of net discounted revenue for every cycle completed by $T_{\max }$ :

$$
C P^{s p}\left(P_{0}, T, T_{\text {max }}\right)=\sum_{n=1}^{n^{s p}}\left(-c P_{0}+p Y\left(T, P_{0}\right)\right) e^{-\delta n T}
$$

192 where $p$ is the price per unit weight (USD/kg), $c$ the per capita cost of stocked juvenile

193 prawns, and $\delta$ the discount rate to account for the time lag between initial stocking costs and

194 delayed revenues of commercial size prawns. Following the comprehensive price analysis by

195 Dasgupta and Tidwell, we set $c=\$ 0.10 / P$ for a juvenile prawn of $L_{0}=40 \mathrm{~mm}$ 
196 (corresponding to $\sim 0.35 \mathrm{~g}$ juvenile prawns) and $p=\$ 12 / \mathrm{kg}$ harvested ${ }^{33}$. The discount rate

197 is set to 7\%, which is likely on the low end for sub-Saharan African countries endemic with

198 schistosomiasis but higher than the 3-4\% rate used for discounting long term government

199 projects in the United States ${ }^{34}$. Other costs such as maintaining nurseries to produce juvenile

200 prawns are considered external to the aquaculture scenario considered here and are

201 therefore not included in the profit estimation. The influence of such costs are considered in

202 additional sensitivity analyses described below.

203 Cumulative discounted profits are maximized by jointly choosing the rotation length, $T$,

204 and the initial stocking density, $P_{0}$. Given the rotation length, the number of rotations in the

205 time period is determined, as $T_{\max }$ is given. Equation 7 has it basis in the optimal rotation

206 models in forestry (see, e.g., ${ }^{35}$ ) and commercial aquaculture operations (see, e.g., ${ }^{36,37}$ ) which

207 balance the marginal benefits of further growth against the opportunity costs of waiting to

208 harvest. The resulting optimal rotation length is therefore shorter than a simple rule of when

209 to harvest based solely on maximizing growth dynamics. In our setting, we expect the same

210 trade-off between benefits from waiting to harvest the prawns at a larger size against the

211 opportunity costs of delaying the economic returns from future harvests.

212 Parameters used in the prawn aquaculture model simulations are listed in Table S1. 


\section{3 (b) Epidemiologic model}

214 Building on our previous modeling of S. haematobium ${ }^{15,38}$, the infection dynamics of the

215 intermediate host snail population, $N$, are modeled as snails transition between $i \in\{S, E, I\}$

216 infection compartments corresponding to susceptible $(S)$, exposed ( $E$, pre-patent), and

217 infected ( $I$, patent) states. Furthermore, the growth dynamics of snails are modeled as they

218 move through $j \in\{1,2,3\}$ size classes corresponding to $4 \mathrm{~mm}, 8 \mathrm{~mm}$, and $12 \mathrm{~mm}$ mean snail

219 diameter (Fig. 1). The model is further extended to include snail migration with a constant

220 migration rate, $\xi$, to and from an external population, $\boldsymbol{N}^{E}$, that is not affected by prawn

221 interventions. For simplicity, the external population is conceptualized to originate from an

222 identical transmission site to the one in which interventions are modeled, though in reality,

223 multiple sites with heterogeneous transmission dynamics may contribute differentially to the

224 intervention site.

225 
<smiles>[C-]=C</smiles><smiles>C1CCCCC1</smiles>

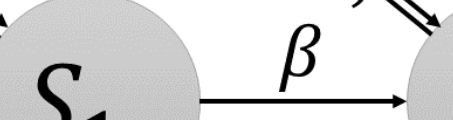

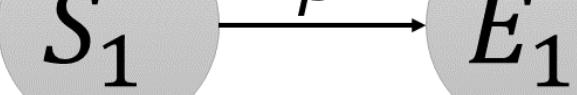

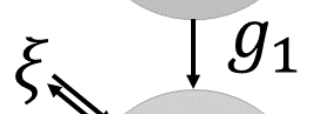
$g_{1}$

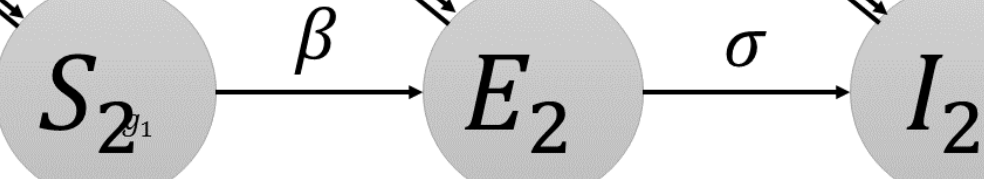

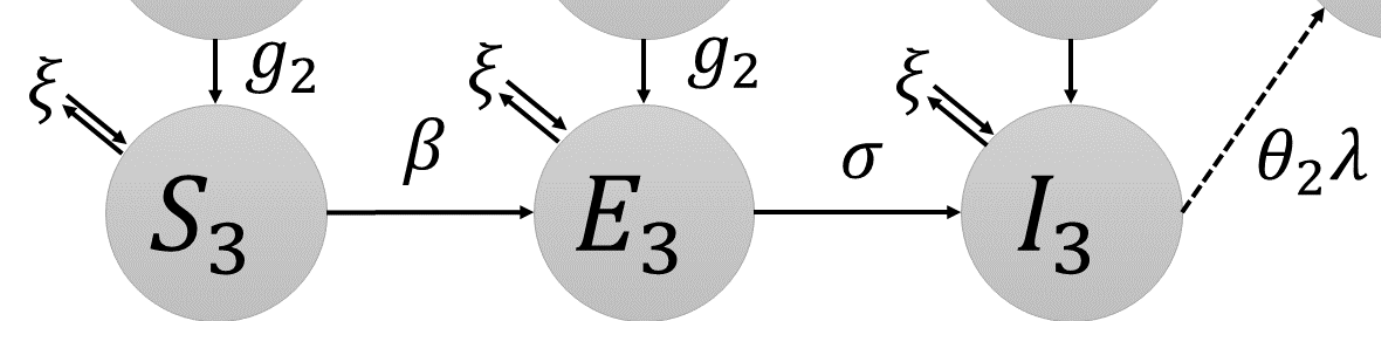

227 Figure 1: Epidemiologic model schematic with snail size and infection classes. Parameters governing transitions between classes and migration into and out of each class are shown. 
New snails enter the population as susceptible juveniles, i.e. in infection class $i=S$ and

231 size class $j=1$. Logistic snail population growth is modeled with per-capita recruitment, $f$,

232 and carrying capacity, $K$. Neither small snails $(j=1)$ nor infectious snails $(i=I)$ contribute

233 to recruitment due to sexual immaturity and parasitic castration, respectively ${ }^{39}$. Pre-patent

234 snails' contribution to recruitment is reduced by a fraction $0<z<1^{40}$. Snails of each size

235 class are subject to both size-dependent natural mortality, $\mu_{j}$, and predation mortality, $\psi_{j}$, a

236 function of both prawn and snail body size and density described in the next section. Small

237 and medium snails grow and transition to the next size class at the per capita rate $g_{1}$ (from

238 size class 1 to 2 ) and $g_{2}$ (from class 2 to 3 ), respectively.

239 New snail infections occur at the per capita rate, $\beta M$, where $\beta$ is the transmission rate

240 and $M=0.5 \phi(W) W H m$ is an estimate of the overall number of Schistosoma miracidia (free

241 living infective stages) produced by mated adult female worms. This estimate is the product

242 of the size of definitive human host population, $H$, the mean parasite burden, $W$, (i.e., mean

243 number of adult worms per person), the rate at which mated adult female worms shed eggs

244 that hatch into infectious miracidia, $m$, and the function $\phi(W)$ representing the density-

245 dependent mating probability of adult worms ${ }^{41}$. The coefficient 0.5 accounts for the assumed

246 1:1 sex ratio of adult worms. For simplicity, we assume a constant human population and no

247 density dependent fecundity of female worms. Following infection, pre-patent snails, $E$,

248 transition to the patent class, $I$, at rate $\sigma$, with $\sigma^{-1}$ being the mean time necessary for

249 sporocyst development following snail infection with a miracidium.

250 The adult parasite population harbored by definitive human hosts is modeled as the mean

251 parasite burden in the human population, $W$, assuming a negative binomial distribution with

252 clumping parameter, $\varphi^{41,42}$. Humans acquire adult worms as a result of contact with cercariae

253 shed from infected snails. Worm acquisition occurs at rate $\lambda$, an aggregate parameter

254 accounting for the per capita shedding rate of cercariae by infected snails, cercariae mortality, 
255 contact rate, and probability of infection, as described in previous work ${ }^{15}$. The cercarial

256 shedding rate of medium $\left(N_{I 2}\right)$ and large $\left(N_{I 3}\right)$ snails is assumed to exceed that of small $\left(N_{I 1}\right)$

257 snails by a factor $\theta_{1}$ and $\theta_{2}$, respectively ${ }^{43}$.

258 The full system of differential equations describing the epidemiologic model can be found

259 in the supplementary information along with model parameters listed in Table S2.

\section{0 (c) Prawn predation model}

261 As in previous work ${ }^{38}$, the per-capita prawn predation rate on snails of each class, $\psi_{i j}$, is

262 modeled as a type III functional response, described by a generalization of Holling's disk

263 equation ${ }^{44}$. This produces a sigmoid-shaped function, which increases and saturates at high

264 prey densities and decreases to approach zero at low prey densities. Previous experiments

265 by Sokolow et al ${ }^{13}$ show that prawn predation of snails changes predictably as a function of

266 the ratio of prawn biomass to snail body mass, $r_{j}$. Using these experimental data, the attack

267 rate, $\alpha$, is estimated as a log-linear function of the biomass ratio: $\alpha=\alpha_{m} * \log \left(r_{j}(t)\right)$. The

268 handling time, $T_{h}$, is estimated as a reciprocal function of the biomass ratio: $T_{h}=$

$269\left(T_{h_{m}} r_{j}(t)\right)^{-1}$ where $\alpha_{m}$ and $T_{h_{m}}$ are coefficients estimated from ${ }^{13}$ and $r_{j}$ the ratio between

270 prawn body size and mean snail body size in each class. Laboratory experiments presented

271 in ${ }^{13}$ show that small prawns are unable to feed on large snails $(j=3)$, accordingly, $\psi=0$

272 when $r_{j}<3$. In addition, the attack rate, $\alpha$, derived by Sokolow et al. ${ }^{13}$ in controlled

273 laboratory conditions in $1 m^{-2}$ tanks is penalized by a factor $0<\epsilon<1$ to account for the

274 reduction in searching efficiency caused by the morphological complexity of foraging in wild

275 settings.

276 The biomass ratio for each snail size class is estimated as:

277

$$
r_{j}(t)=\frac{B(t)}{a_{N} L_{N_{j}}^{b_{N}}}
$$


278 where $B(t)$ is prawn body size derived with eq. (4), and the denominator represents snail

279 mass in each class $j$, derived as a simple allometric function of snail shell diameter in each size

280 class. The per-capita attack rate of prawns on snails of size $j$ and infection class $i$ is then

281 estimated as:

$$
\psi_{i j}=\left\{\begin{array}{cc}
\frac{\alpha\left(r_{j}(t)\right) \epsilon N_{i j}^{n}}{1+\sum_{i=S}^{I} \sum_{j=1}^{3} \alpha\left(r_{j}(t)\right) \epsilon T_{h}\left(r_{j}(t)\right) N_{i j}^{n}}, & r_{j} \geq 3 \\
0 & r_{j}<3
\end{array}\right.
$$

283 Prawn stocking at the considered densities is assumed to have no negative effects on

284 water quality that may affect prawn survival, growth, predation of snails, or snail population

285 dynamics, though ongoing field experiments in the lower Senegal River basin show that water

286 quality may be negatively affected by nets installed to contain prawns introduced at

287 transmission sites.

288 Parameters of the snail predation component of the combined model are listed in Table S3.

\section{Model simulations}

290 We consider a time horizon of $T_{\max }=10$ years, for comparability to similar analyses

291 investigating different schistosomiasis intervention strategies 7,45. Because prawn body size

292 increases and levels off with time (eq. 1-3), but prawn abundance decreases in time (eq. 5),

293 both stock biomass and cumulative profit (eq. 7) are unimodal functions of time for any given

294 initial stocking density, $P_{0}$. Additionally, harvesting prior to peak profit may afford the

295 opportunity to increase $n^{s p}$ and therefore sacrifice short term profits to maximize long term

296 profit. It is thus possible to use equations 1-7 to simulate prawn aquaculture dynamics and

297 numerically find the stocking density, $P_{0}$, and harvest time, $T$, that maximize cumulative

298 profit. The surface of values $\left(P_{0}, T, C P^{s p}\left(P_{0}, T, T_{\max }\right)\right)$ is related to the eumetric curve used in

299 fishery science to identify the stocking density that maximizes profit ${ }^{46}$. As stocking costs

300 increase linearly with stocking size, $P_{0}$, while revenues increase less than linearly as a 
301 consequence of density-dependent growth and mortality, the surface is unimodal and its

302 peak represents the maximum achievable cumulative profit, $C P_{o p t}^{s p}=$

$303 \max \left(C P^{s p}\left(P_{0}, T, T_{\max }\right)\right)$. Therefore, for each Macrobrachium species $(s p)$ and a time period

304 of $T_{\max }=10$ years it is possible to identify the stocking density, $P_{0}{ }_{o p t}$, and harvest time, $T_{o p t}^{s p}$,

305 that maximize cumulative profit, $C P_{o p t}^{s p}$, here collectively defined as optimal management. We

306 identify optimal management for each prawn species using a grid search over initial stocking

307 densities, $P_{0}$, ranging between $0.5-7.5 \mathrm{Pm}^{-2}$ and potential harvest times, $T$, on each day

308 between $1-730$.

309 Given the optimal stocking density, $P_{0}{ }_{\text {opt }}^{s p}$, that maximizes cumulative profit and the

310 corresponding optimal harvest time in an individual cycle, $T_{o p t}^{s p}$, the epidemiologic model is

311 run under the following scenarios: (1) 10 years of annual MDA with no prawn intervention;

312 (2) and (3); 10 years of prawn stocking and harvesting under optimal aquaculture

313 management for each species, as described above; and (4) and (5) 10 years of integrated

314 annual MDA and prawn intervention under optimal management. In all scenarios, we

315 simulate the system for an additional 10 years without intervention to explore the potential

316 for infection rebound in the case the intervention program is ceased.

317 Stocking and harvesting were simulated at regular intervals of $T_{o p t}^{s p}$ days, and were

318 implemented as instantaneous events that reset the values of $P$ and $L$ to match the initial

319 conditions at the beginning of each stocking cycle (i.e. $P_{0_{o p t}}^{s p}$ and $L_{0}$ ). This assumes that all

320 prawns-regardless of marketability-are harvested and replaced with $P_{0} s p$ opt juveniles in a

321 single day. Mass drug administration is implemented as an instantaneous 85\% reduction in

322 mean worm burden, $W$, in the same $75 \%$ of the human population, corresponding to

323 assumptions of $85 \%$ drug efficacy and 25\% systematic non-compliance 45,47 . 
324 To compare the effects of different interventions, we model disability associated with

325 schistosomiasis using the disability adjusted life year (DALY) as in previous analyses 7,48.

326 Disability weights measuring the disability associated with a condition for a single year of

327 life-where 0 is perfect health and 1 is death-were distributed among individuals with

328 heavy ( $>50$ eggs per $10 \mathrm{~mL}$ urine, $\left.H_{h i}\right)$ and light $\left(0<\right.$ eggs per $10 \mathrm{~mL}$ urine $\left.\leq 50, H_{l o}\right) S$.

329 haematobium burdens as defined by WHO guidelines. Total DALYs over the simulation period

330 are then estimated as:

$$
\sum_{t=1}^{T_{\max }} \frac{D W_{h i}}{365} H_{h i_{t}}+\frac{D W_{l o}}{365} H_{l o_{t}}
$$

331 Where $D W_{h i}$ and $D W_{l o}$ are the yearly disability weights associated with heavy and light $S$.

332 haematobium burdens, respectively, normalized to a daily estimate to match the dynamics of

333 the epidemiological component of the model. Details on estimating the number of individuals

334 in each burden class at each time step of the epidemiological model $\left(H_{h i_{t}}\right.$ and $\left.H_{l o_{t}}\right)$ are

335 provided in the supplementary information.

336 The model was coded in R version 3.5.0 and simulated using the solver lsoda from the

337 package deSolve ${ }^{49}$. To address concerns regarding reproducibility, all model code and data

338 are included as a supplementary file and are also made freely available online at

339 https://github.com/cmhoove14/Prawn fisheries Public health.

\section{Sensitivity analyses}

341 To quantify the influence of uncertain parameter inputs on key model outcomes, latin

342 hypercube sampling is performed over parameter ranges in Table S1 to generate a set of

3431,000 candidate sets. These parameter sets are used to derive estimates of uncertainty in the

344 simulations described above. Furthermore, global sensitivity analysis using latin hypercube

345 sampling and partial rank correlation coefficients (LHS-PRCC) ${ }^{50,51}$ is performed with optimal 
346 cumulative profit $\left(C P_{o p t}^{s p}\right)$ as the outcome in the prawn aquaculture model, equilibrium

347 infected snail density $\left(N_{I}\right)$ and mean worm burden $(W)$ absent prawn or MDA interventions

348 as the outcomes in the epidemiologic model, and total DALYs accumulated through simulated

349 10-year combined MDA and prawn interventions as the outcome in the integrated model.

350 Briefly, PRCC estimates the correlation between a model parameter and a model outcome by

351 first rank-transforming parameters drawn from an LHS scheme and the corresponding model

352 outputs, then removing the linear effects of all other model parameters on the parameter of

353 interest and the outcome, and finally measuring the linear relationship between the rank-

354 transformed parameter and outcome residuals ${ }^{50}$. Monotonicity of the relationship between

355 model outputs and all parameters was assessed via scatterplots (Figs S1-S4) prior to

356 conducting LHS-PRCC sensitivity analyses.

357 Two additional sensitivity analyses are performed to identify profitability thresholds for

358 the prawn aquaculture model. In the first, fixed costs, $c_{f}$, in the range $\$ 0-\$ 1,000$ are added

359 to the per-cycle profit calculation (eqn 7; such that total cost for each cycle is $-\left(c P_{0}+c_{f}\right)$ ) to

360 represent additional costs that may be incurred with each aquaculture cycle such as labor,

361 transport of prawns, and nursery costs leading up to stocking. In the second, the prawn

362 mortality rate, $\mu_{P}$, is multiplied up to 10 times the estimated natural rate to account for

363 additional sources of prawn loss that may be incurred due to predation, escape, or other

364 sources of mortality, such as disease.

\section{$365 \underline{\text { Results }}$}

\section{Aquaculture model}

367 With parameters fixed at the values shown in Table 1 , stocking $M$. rosenbergii at $P_{0}=$

$3682.6 \mathrm{Pm}^{-2}$ and harvesting at $T_{o p t}^{\text {ros }}=165$ days maximizes cumulative ten-year profit while

369 stocking at $P_{0}=2.4 \mathrm{Pm}^{-2}$ and harvesting at $T_{o p t}^{\text {ros }}=260$ days maximizes cumulative profit 
370 for M. vollenhovenii. These stocking densities and harvesting times were used to simulate

371 aquaculture cycles for each species. Figure 2 shows the dynamics of each species run

372 continuously through two years with vertical dashed lines indicating the optimal time of

373 harvest, $T_{o p t}^{s p}$. Prawns grow in length, $L$, and weight over time while population size

374 (measured as density, $\mathrm{Pm}^{-2}$ ) decreases with time as a result of density dependent death from

375 crowding and natural, size-dependent mortality (Fig 2). These competing effects lead to a

376 humped function of total harvestable biomass, $\Omega$, over time with the peak occurring well

377 before prawns grow to their full size. Ten-year cumulative profits also have a single peak,

378 which is determined both by the profit per cycle and the number of cycles possible within the

37910 year time frame. Cumulative profits are maximized by harvesting well before the peak in

380 harvestable biomass occurs, indicating more, smaller harvests maximize profit over time. 


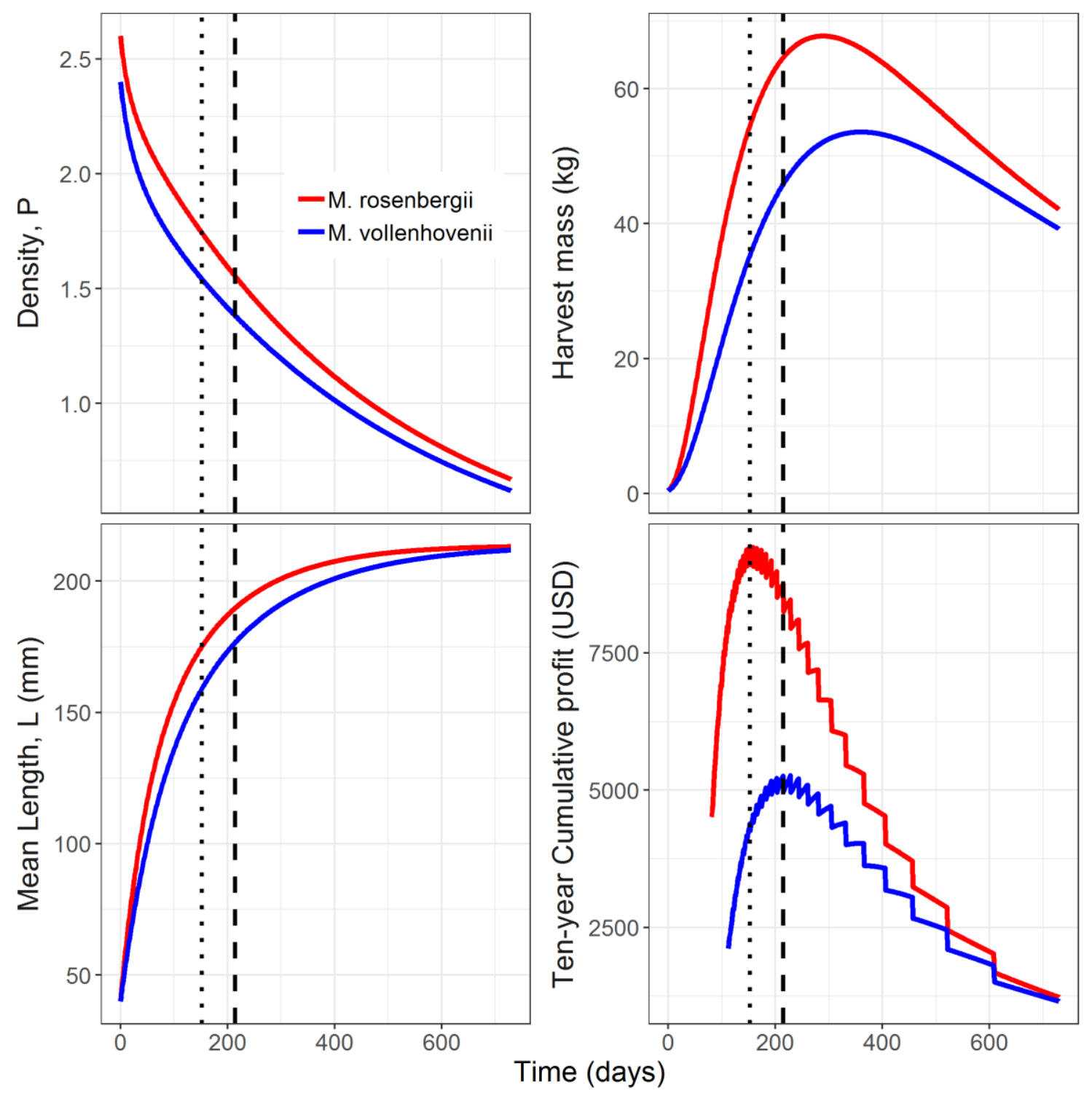

Figure 2: Prawn aquaculture model dynamics. Two-year aquaculture cycles for, M. rosenbergii (red lines) and M. vollenhovenii (blue lines) under optimal management showing how prawns grow in length over time (bottom-left), but decrease in density (top-left). This leads to a single peak in harvest mass (top-right), but harvesting actually occurs prior to the peak in order to maximize tenyear cumulative profits (bottom-right) by sacrificing profit-per-cycle for completing more aquaculture cycles. Vertical dashed lines indicate time at which harvest would occur for each species (small dashes - M. rosenbergii, large dashes $-M$. vollenhovenii). Here, following (19), we set the cost $c$ for a juvenile prawn to $\$ 0.10$ with $L_{0}=40 \mathrm{~mm}(\sim 0.35 \mathrm{~g}$ per juvenile prawns) and selling price $\mathrm{p}=\$ 12 / \mathrm{kg}$. Other parameters set as in Table 1 . 
392 The surface of values $\left(P_{0}, T, C P^{s p}\left(P_{0}, T, T_{\max }\right)\right)$ for each species is shown in Figure 3. As

393 expected, profits associated with aquaculture of the faster growing $M$. rosenbergii are higher.

394 Considering parametric uncertainty, the peak estimate of median cumulative profit for $M$.

395 rosenbergii occurs at $P_{0}=2.9 \mathrm{Pm}^{-2}$ and $T_{o p t}^{\text {ros }}=173$ days (IQR: $146-192$ ), producing

$396 C P_{o p t}^{\text {ros }}=\$ 5364(\$ 3192-\$ 8111)$ per $1,000 \mathrm{~m}^{2}$ enclosure. The same estimates for

397 M. vollenhovenii are $P_{0}=2.5 \mathrm{Pm}^{-2}, \quad T_{o p t}^{v o l}=260$ days $(228-331)$, and $C P_{o p t}^{v o l}=$

398 \$1738 (\$704-\$3394). Additional outputs from the aquaculture model that describe stock

399 structure and aquaculture performances at optimal management are reported in Table 1. 
bioRxiv preprint doi: https://doi.org/10.1101/465195; this version posted November 9, 2018. The copyright holder for this preprint (which was not certified by peer review) is the author/funder, who has granted bioRxiv a license to display the preprint in perpetuity. It is made available under aCC-BY-ND 4.0 International license.

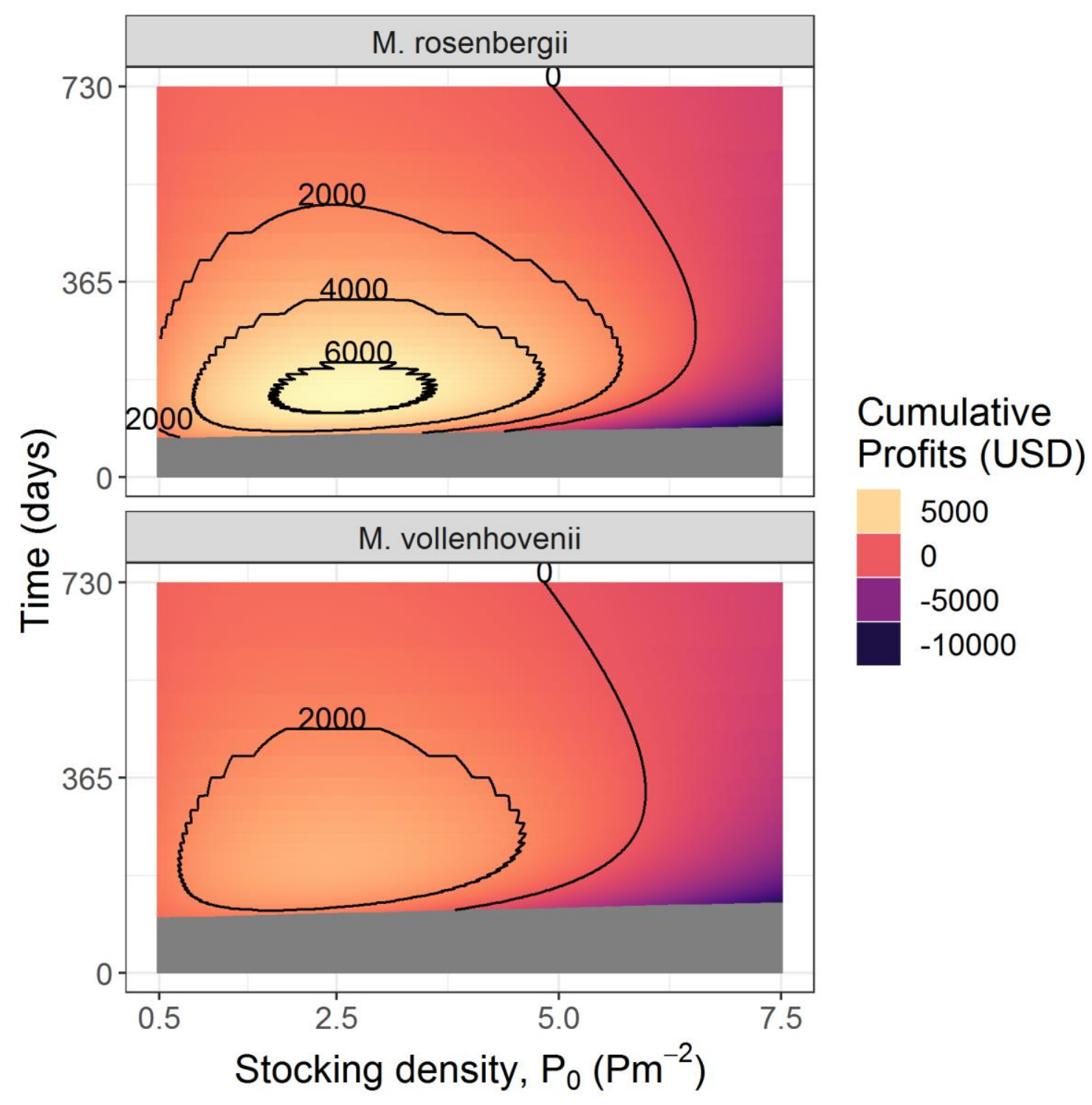

402 Figure 3: Grid search to identify optimal management decisions for each prawn species. Cumulative profits $\left(C P^{s p}\right)$ generated by the aquaculture model for each species across a range of potential stocking densities $\left(P_{0}\right)$ and harvest times $(T)$ are shown. Grey regions indicate regions where harvesting is not feasible due to prawns not having reached sufficient marketable size $(30 \mathrm{~g})$. Contours indicate regions of $C P^{s p}$ corresponding to the labeled value in 2018 USD. 
bioRxiv preprint doi: https://doi.org/10.1101/465195; this version posted November 9, 2018. The copyright holder for this preprint (which was not certified by peer review) is the author/funder, who has granted bioRxiv a license to display the preprint in perpetuity. It is made available under aCC-BY-ND 4.0 International license.

408 Table 1: Optimal stocking and harvesting parameters for each prawn species reported as median 409 (interquartile range).

\begin{tabular}{|c|c|c|c|}
\hline Parameter & Definition & M. vollenhovenii & M. rosenbergii \\
\hline$P_{0_{o p t}}^{s p}$ & Optimal stocking density & $2.4 \mathrm{Pm}^{-2}$ & $2.6 \mathrm{Pm}^{-2}$ \\
\hline$L_{0}$ & Stocking size of juveniles & $40 \mathrm{~mm}$ & $40 \mathrm{~mm}$ \\
\hline$T_{o p t}^{S p}$ & Optimal harvest time & $\begin{array}{c}260 \text { days } \\
(228-331)\end{array}$ & $\begin{array}{c}165 \text { days } \\
(146-192)\end{array}$ \\
\hline$L\left(T_{o p t}^{s p}\right)$ & Mean length at harvest & $\begin{array}{c}167 \mathrm{~mm} \\
(161-175)\end{array}$ & $\begin{array}{c}167 \mathrm{~mm} \\
(161-174)\end{array}$ \\
\hline$P\left(T_{o p t}^{s p}\right)$ & Prawns harvested & $\begin{array}{c}1056 \\
(850-1236)\end{array}$ & $\begin{array}{c}1559 \\
(1434-1662)\end{array}$ \\
\hline$Y\left(T_{o p t}^{s p}, P_{0}^{s p}\right)$ & Commercial yield per harvest & $\begin{array}{c}28 k g \\
(21-36)\end{array}$ & $\begin{array}{c}41 k g \\
(34-49)\end{array}$ \\
\hline$n^{s p}$ & Number of cycles in 10 years & $\begin{array}{c}14 \\
(11-16)\end{array}$ & $\begin{array}{c}22 \\
(19-25)\end{array}$ \\
\hline$C P_{o p t}^{s p}$ & $\begin{array}{c}\text { Cumulative profits over } 10 \\
\text { years }\end{array}$ & $\begin{array}{c}\$ 1891 \\
(\$ 856-\$ 3486)\end{array}$ & $\begin{array}{c}\$ 5403 \\
(\$ 3380-\$ 8075)\end{array}$ \\
\hline
\end{tabular}

410 


\section{Integrated aquaculture epidemiologic model}

413 Simulation of the integrated model reveals comparable performance of prawn

414 intervention strategies to MDA strategies. As in previous analyses 7,15 , annual mass drug

415 administration alone produces a pattern of gradually decreasing worm burden over time

416 characterized by repeated rebound in infection following MDA (Fig 4A, purple line). The

417 prawn-only intervention causes mean worm burden to gradually decline towards 0 ,

418 eventually reducing worm burden to comparable levels by year 10 (Fig 4A, blue line). Finally,

419 the combined MDA and prawn intervention leads to a rapid decline in mean worm burden

420 that nearly reaches 0 by year 10 (Fig 4A, gold line).

421 These patterns can mostly be explained by the underlying snail infection dynamics. Under

422 MDA intervention, the snail population persists through repeated rounds of MDA and even

423 increases due to the reduced influence of infection (Fig 4B). Most importantly, a population

424 of infected snails is able to sustain transmission - albeit at lower levels-even as adult worms

425 are removed from the treated human population by MDA (Fig 4B). Interventions in which

426 prawns are introduced at profit-optimal densities produce rapid declines in the snail

427 population that heavily reduce this environmental reservoir of transmission (Fig 4C).

428 Extirpation of the entire snail population is prevented due to the assumption of a Holling's

429 type III functional response and immigration from an unaffected reservoir population (see

430 Fig S3 for snail infection dynamics without immigration and under a Holling's type II

431 functional response), but transmission is effectively halted due to near elimination of the

432 infected snail population (Fig 4C). This heavy reduction in transmission coupled with the

433 benefits of MDA translates to near elimination of the parasite by year 10. Regardless of the

434 intervention, ceasing efforts to control transmission after 10 years results in rapid returns to

435 pre-intervention snail populations and community-level mean worm burdens (Fig 4A-C). 
bioRxiv preprint doi: https://doi.org/10.1101/465195; this version posted November 9, 2018. The copyright holder for this preprint (which was not certified by peer review) is the author/funder, who has granted bioRxiv a license to display the preprint in perpetuity. It is made available under ACC-BY-ND 4.0 International license.
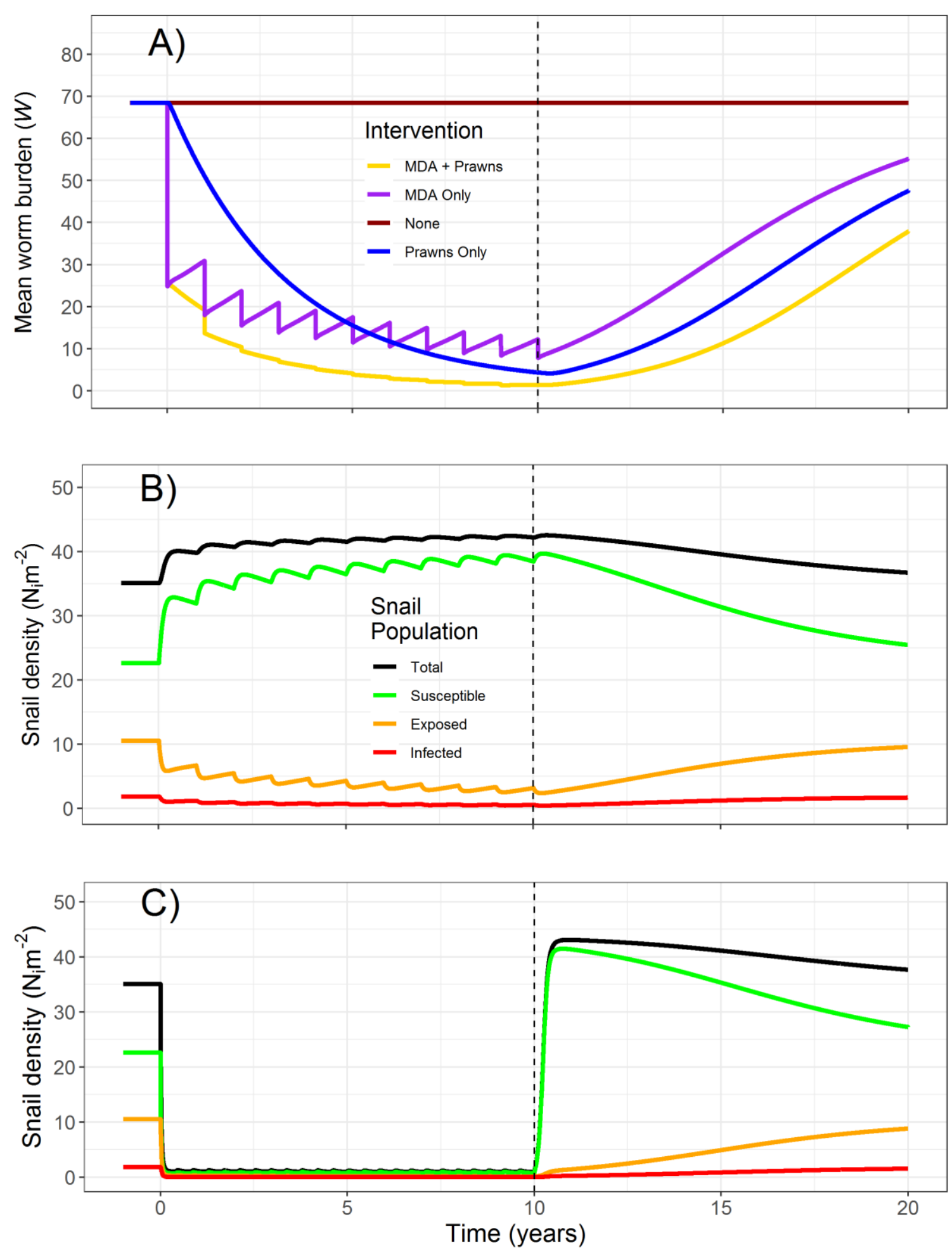

Figure 4: Outputs of the integrated model under different intervention scenarios implemented over ten years followed by ten years of no intervention. Worm burden trajectories under no intervention (red), annual MDA only (purple), prawn stocking of M. rosenbergii under optimal management (blue), and both annual MDA and prawn stocking (gold) (A); snail infection dynamics under MDA only intervention (B); and snail infection dynamics under prawn stocking interventions (C). Outputs from M. volenhovenii interventions not shown as they approximately mirror those of M. rosenbergii. 
443 Comparison of total DALYs lost over ten year simulation periods under each intervention

444 shows comparable performance of the prawn only intervention to MDA and ubstantial

445 additional DALYs averted when combining MDA with prawn intervention. Without

446 intervention a median 324 (IQR: 119 - 502) DALYs are lost to S. haematobium infection.

447 Annual MDA and profit-optimal stocking of prawns perform comparably with 160 (IQR: 54 -

448285 ) total DALYs lost with annual MDA and 184 (IQR: 70 - 294) total DALYs lost with profit-

449 optimal prawn stocking; representing 51\% and 43\% DALYs averted, respectively. Integrated

450 interventions utilizing both MDA and prawn stocking reduce median DALYs lost to 83 (IQR:

$45130-137)$, representing a 74\% reduction in S. haematobium related disability.

\section{Sensitivity Analyses}

453 Substantial sensitivity analyses reveal that profitability of the prawn aquaculture system

454 and reductions in schistosomiasis burden associated with prawn introductions are robust to

455 model assumptions and parameters (Figs S1 and S2). The addition of fixed costs associated

456 with each aquaculture cycle and additional sources of mortality reveal aquaculture of $M$.

457 rosenbergii remains profitable with fixed costs of up to $\$ 550$ per cycle (Fig S1) and mortality

458 rates up to 5.2 times higher than the baseline estimate (Fig S2). Aquaculture of $M$.

459 vollenhovenii remains profitable with fixed costs of up to $\$ 400$ per cycle (Fig S1) and

460 mortality rates up to 3.6 times higher than the baseline estimate (Fig S2). Global sensitivity

461 analysis using LHS-PRCC shows that the parameters of the VBGE that govern prawn growth

462 dynamics $\left(L_{\infty}, \kappa\right)$ and parameters governing estimates of discounted profits $(\delta, p)$ are most

463 correlated with 10-year cumulative profits (Fig 5B)

464 Exploration of snail infection dynamics under prawn interventions also reveals that the

465 Holling's type III functional response and the inclusion of snail migration represent

466 conservative structural model assumptions. Figure S3 shows that snail extirpation is only

467 possible when both of these assumptions are relaxed. Parameters governing snail predation 
468 by prawns $(\epsilon, n)$ are also shown to have moderate influence on estimates of 10-year

469 cumulative DALYs lost (Fig 5A).

470 Key outcomes from the epidemiologic model including equilibrium estimates of infected

471 snail density $(I)$ and mean worm burden $(W)$ and of DALYs lost over 10-year intervention

472 periods is mostly influenced by epidemiologic parameters, rather than parameters governing

473 prawn population or predation dynamics (Fig 5A \& 5C). We also compared parameter sets in

474 which the MDA only intervention was superior to the prawn only intervention in terms of

475 DALYs averted. We find that the MDA only intervention leads to more DALYs averted when

476 the coverage and efficacy are high, while the prawn-only intervention performs better when

477 the snail population carrying capacity $(K)$ is higher (Fig S4). 

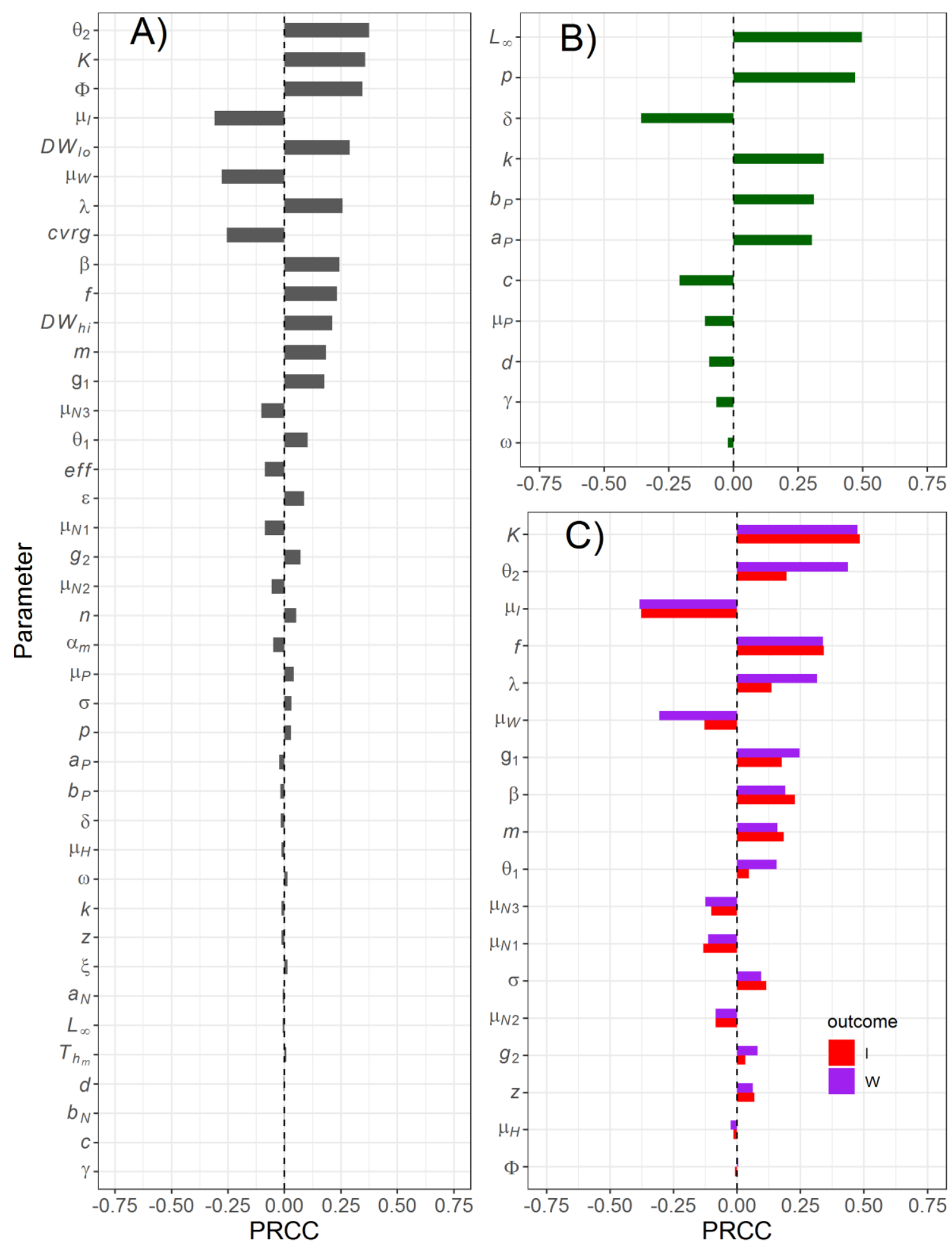

Figure 5: Sensitivity of key model outcomes to model parameters assessed with LHS-PRCC. Sensitivity to all parameters of DALYs lost following 10 years of combined MDA and prawn intervention (A), cumulative 10-year profit sensitivity to prawn aquaculture parameters (B), and sensitivity of mean worm burden and equilibrium infected snail density to epidemiologic parameters (C). Parameter definitions and baseline values can be found in supplementary tables 1-3. 


\section{Discussion}

487 Small-scale, extensive prawn aquaculture such as that considered here offers a profitable

488 and sustainable method to improve food production, reduce schistosomiasis burdens, and

489 increase revenues for small-scale subsistence farmers, especially when paired with ongoing

490 efforts such as rice cultivation ${ }^{25}$. In areas of high food insecurity, malnutrition, and endemic

491 schistosomiasis-conditions which reinforce each other and often result in "poverty traps"

492 52,53_an integrated system of prawn aquaculture may be a solution for co-benefits of disease

493 control and sustainable development.

494 Our results are consistent with an increasing body of evidence that consumption of snails

495 by predator species such as Macrobrachium prawns can be an effective method for combating

496 schistosomiasis transmission to people $14,15,54$. Specifically, by targeting the environmental

497 reservoir of schistosome parasites, prawns can reduce reinfection rates that plague MDA

498 campaigns in high transmission settings. By deploying prawn aquaculture with MDA,

499 effective control-in which the schistosome parasite is suppressed in both human hosts and

500 intermediate host snails—can be achieved.

501 We also show that such prawn interventions combined with established extensive

502 aquaculture methods can be profitable if carefully managed. Drawing on economic studies of

503 existing aquaculture practices ${ }^{19,33}$, we develop — to our knowledge - the first dynamic model

504 of prawn aquaculture to investigate optimal management practices. The model suitably

505 simulates prawn stocking in a large water contact site or rice paddy, and the length of optimal

506 cycles coincides with typical rice harvesting timelines ${ }^{25}$. We find that this system produces

507 short- and long-term profits, implying the potential for a sustainable, community-driven

508 intervention, given the right capital investment and incentive programs.

509 Under optimal management, extensive aquaculture of of either $M$. rosenbergii or $M$.

510 vollenhovenii leads to both profits and reductions of the snail population. The optimal 
511 stocking densities of each species are above the potential threshold of approximately $2 \mathrm{Pm}^{-2}$

512 necessary for local snail extirpation as identified in previous work ${ }^{15}$, though our conservative

513 inclusion of snail migration and a Holling's type III functional response restricts such an

514 outcome in this analysis.

515 Achieving these stocking densities may be challenging in sub-Saharan Africa where $>90 \%$

516 of the global burden of schistosomiasis is found ${ }^{23}$ and where the proposed intervention is

517 likely to provide the most benefit. More than 50 years of domestication of M. rosenbergii has

518 established protocols for ideal rearing and management of aquaculture efforts with this

519 species 18,19 , whereas similar protocols for the African native M. vollenhovenii are still under

520 development. Profits appear to be highly sensitive to parameters that regulate prawn growth,

521 meaning continued research and development into $M$. vollenhovenii aquaculture may

522 eventually provide comparable profits to M. rosenbergii. However, in the short term, all male

523 stocking of $M$. rosenbergii may be a superior strategy.

524 This strategy of stocking the non-native M. rosenbergii in coastal regions where it is non-

525 native should be approached with caution to avoid the establishment of an alien population

526 with potentially unintended ecological consequences on local biodiversity. Establishment of

527 non-GMO aquaculture biotechnologies for either all-male ${ }^{55-57}$ or all-female ${ }^{58}$ populations

528 suggest possible strategies to prevent invasions. Moreover, recent laboratory experiments

529 (Savaya-Alkalay et al. submitted) have ruled out the possibility of cross-fertilization between

530 mature female M. vollenhovenii and male M.rosenbergii, demonstrating that male-only

531 progeny of M. rosenbergii may be safely used for extensive aquaculture and schistosomiasis

532 control in western Africa where M. rosenbergii is non-native.

533 Extensive sensitivity analyses reveal that key model outcomes including profit generated

534 by the aquaculture portion of the model and DALYs lost from the integrated model are robust

535 to key parameters that govern profit estimation and the influence of prawn interventions on 
536 DALYs lost. The prawn aquaculture model is most sensitive to parameters governing somatic

537 growth, which have been estimated from available literature, and supported by expert

538 opinion 28,32. This finding also suggests that if stock improvement or improvements in

539 husbandry practices can increase average prawn condition or size, i.e. by supplementing

540 feeds, further increases in profit may be possible. Selective harvesting methods that only

541 remove market-size prawns, leaving the remaining stock to continue to grow, may also

542 improve aquaculture performance.

543 Optimal aquaculture practices are also sensitive to the market price of adult prawns and

544 the stocking cost of juvenile prawns, implying that optimal management may be influenced

545 by fluctuations in market factors that may influence price and cost of harvested and stocked

546 prawns. Profit generated from selling harvested prawns is based on reasonable assumptions

547 of prices in premium markets, though the actual selling price in subsistence economies might

548 be lower and contingent on market access and local demand. However, the fixed cost

549 sensitivity analysis demonstrates profitability is possible even with substantial additional

550 costs associated with prawn stocking, and profitability persists across a wide range of

551 stocking densities for each species. These results together assuage concerns that such

552 vagaries of the market would impair the success of the proposed system and suggest that

553 prawn aquaculture should be economically viable even under non-optimal management

554 densities.

555 Additional sources of mortality could result from declines in water quality caused by

556 prawn stocking, disease outbreaks, or predation by waterbirds, fish, amphibians or reptiles.

557 We demonstrate that extensive aquaculture is still profitable with mortality rates as high as

558 five times greater than natural mortality. Barring catastrophic events, this demonstrates that

559 the proposed system should be resilient to such perturbations. Therefore, further field work

560 is required to assess prawn life expectancy, escapement rate, growth performances, changes 
561 in water quality, and potential changes in human behavior which might affect either

562 aquaculture performances and/or snail abundance, transmission rates, and epidemiologic

563 outcomes.

564 Prawn predation of the snail population as modeled here is also based on a number of

565 assumptions including the Holling's type III functional response and the prawn attack rate

566 penalty. We consider the type III functional response a conservative estimate of the

567 relationship between prawn predation and snail density as it does not allow for the potential

568 extirpation of the snail population. We also test a wide range of attack rate penalties as we

569 identified no prior estimates of prawn predation efficiency in non-laboratory settings, and

570 find that effective control is feasible even when increasing this parameter by an order of

571 magnitude (implying a substantially reduced attacked rate).

572 Regarding schistosomiasis transmission dynamics, recent findings suggest non-

573 linearities in the human-to-snail force of infection may decrease the efficacy of MDA and lead

574 to faster post-MDA rebounds of schistosomiasis ${ }^{59}$. While this may alter the effects of MDA in

575 our simulations, we believe it strengthens the argument for strategies that explicitly target

576 the intermediate host snail population, such as the prawn intervention proposed here.

577 Another recent finding suggests that snail control can actually lead to increased human risk

578 of Schistosoma infection if the snail population is limited by resource competition prior to

579 "weak" control efforts ${ }^{60}$. In this scenario, remaining snails with higher per-capita resource

580 availability may produce more cercariae. Given the large magnitude of snail reductions at the

581 proposed prawn densities modeled here-even given the conservative Holling's III functional

582 response-we believe this effect is unlikely in our scenarios. Finally, our model lacks

583 seasonality, which would likely affect both schistosomiasis transmission and prawn growth

584 as e.g. temperature and rainfall fluctuate through the year, especially in sub-tropical and near

585 temperate regions where schistosomiasis is still endemic, such as in northern Africa 61,62. 
586 This bioeconomic analysis shows that an integrated intervention strategy that utilizes

587 both MDA and a profitable prawn aquaculture system can successfully control

588 schistosomiasis while generating profit. Since the intervention is driven by a profitable

589 business model, it may be sustainable purely through market incentives, and thereby reduce

590 the need for external support from donors or public health agencies. Subsidies are only likely

591 to be necessary in the event that M. rosenbergii aquaculture is not suitable for the region and

592 obtaining large quantities of M. vollenhovenii juveniles is infeasible or expensive. Research

593 and development for this system is indeed ongoing in Senegal, which will aid future analyses

594 of the effectiveness and feasibility of this promising integrated strategy. 


\section{Data Availability}

596 All data and code used to conduct this analysis are provided as a supplementary file and are 597 freely available at https://github.com/cmhoove14/Prawn fisheries Public health

\section{Acknowledgements}

599 CMH, JVR, GADL, IJJ, AJL, SHS, and JRR were supported by the National Institutes of Health 600 grant no. R01TW010286 (to JRR and JVR). CMH and JVR were additionally supported in 601 part by the National Science Foundation Water, Sustainability and Climate grants 1360330 602 and 1646708 (to JVR), by National Institutes of Health grant no. R01AI125842 (to JVR), and 603 by the University of California Multicampus Research Programs and Initiatives award MRP604 17-446315 (to JVR). GADL, IJJ, AJL and SHS were additionally funded by a grant from the Bill 605 and Melinda Gates Foundation (OPP1114050) and by a GDP SEED grant from the Freeman 606 Spogli Institute at Stanford University. GADL, IJJ, AJL, SHS, and JNS were also supported by 607 NSF CNH grant \#1414102. GADL, SHS, CMH, JVR, JNS, RC, LM and MG were supported also 608 by NIMBioS through the working group on the Optimal Control of Environmentally

609 Transmitted Disease. JPS and AR acknowledge funds provided by the Swiss National Science

610 Foundation, via the project "Optimal control of intervention strategies for waterborne 611 disease epidemics" (200021-172578/1). CLW was supported by the Michigan Society of 612 Fellows at the University of Michigan and by a Sloan Research Fellowship from the Alfred P. 613 Sloan Foundation. RC and LM were also supported by Politecnico di Milano through the 614 Polisocial Award programme (project MASTR-SLS).

\section{Author information}

\section{Contributions}

617 GADL and SHS conceived the problem and designed the general modelling framework. CMH, 618 SHS, JK, JVR, and GADL developed the analysis. CMH and JK wrote the simulations scripts. GR 619 collected field data to parameterize the epidemiologic model. SHS provided experimental 620 data to parameterize the predation component of the model. JNS provided guidance on profit 621 estimation of the prawn aquaculture model. AS-A, SC, and AS provided guidance on dynamics 622 of the aquaculture model. CMH, JK, JNS, JVR, and GADL drafted the manuscript and all authors 623 contributed to its editing.

\section{Competing interests}

625 The authors declare no competing interests 


\section{Supplementary Information}

628 Table S1: Parameters of the prawn aquaculture model and ranges used in the global sensitivity 629 analysis

\begin{tabular}{|c|c|c|c|c|}
\hline Parameter & $\begin{array}{l}\text { Value \& } \\
\text { Units }\end{array}$ & Description & Source & Range \\
\hline $\boldsymbol{L}_{\infty}$ & $214 \mathrm{~mm}$ & $\begin{array}{l}\text { Maximum length used in von } \\
\text { Bertalanffy growth equation }\end{array}$ & 32 & {$[184,234]$} \\
\hline \multirow{2}{*}{$\boldsymbol{\kappa}$} & $0.0034 \frac{\mathrm{mm}}{\mathrm{day}}$ & $\begin{array}{l}\text { Growth rate of } \\
\text { Macrobrachium } \\
\text { vollenhovenii }\end{array}$ & 32,63 & \multirow[t]{2}{*}[0.0078,0.012]{} \\
\hline & $0.0104 \frac{\mathrm{mm}}{d a y}$ & $\begin{array}{c}\text { Growth rate of } \\
\text { Macrobrachium rosenbergii }\end{array}$ & 29 & \\
\hline$\gamma$ & $3.5 \times 10^{-6} g^{-1}$ & $\begin{array}{l}\text { Density dependent growth } \\
\text { reduction }\end{array}$ & 26 & $\begin{array}{l}{\left[3.5 \times 10^{-6}\right.} \\
\left.6.5 \times 10^{-6}\right]\end{array}$ \\
\hline$a_{P}$ & 0.00244 & $\begin{array}{l}\text { Allometric parameter for } \\
\text { Macrobrachium length- } \\
\text { weight conversion }\end{array}$ & \multirow{2}{*}{28} & {$[0.066,0.081]$} \\
\hline$b_{P}$ & 3.55 & $\begin{array}{l}\text { Allometric parameter for } \\
\text { Macrobrachium length- } \\
\text { weight conversion }\end{array}$ & & {$[3.46,3.64]$} \\
\hline$\mu_{P}^{\dagger}$ & $0.0061 \frac{P}{d a y}$ & Daily prawn mortality rate & 32,63 & {$[0.0054,0.012]$} \\
\hline$d$ & -0.382 & $\begin{array}{l}\text { Size-dependent mortality } \\
\text { scaling coefficient }\end{array}$ & 31 & {$[-0.461,-0.289]$} \\
\hline$\omega$ & $5.5 \times 10^{-9} g^{-1}$ & $\begin{array}{l}\text { Density dependent mortality } \\
\text { factor }\end{array}$ & 26 & $\begin{array}{l}{\left[7.5 \times 10^{-9}\right.} \\
\left.3.5 \times 10^{-9}\right]\end{array}$ \\
\hline$p$ & $\frac{\$ 12}{k g}$ & $\begin{array}{l}\text { Price per kg of harvested } \\
\text { market-size prawns }\end{array}$ & $33,64,65$ & {$[11,22]$} \\
\hline$\delta$ & $\frac{1.99 \times 10^{-4}}{\text { day }}$ & Discount rate & (7\% annual) & {$[3 \%, 20 \%]$} \\
\hline $\boldsymbol{c}^{\dagger}$ & $\frac{\$ 0.10}{P}$ & $\begin{array}{c}\text { Cost of a stocked juvenile } \\
\text { prawn }\end{array}$ & 33 & {$[0.045,0.12]$} \\
\hline
\end{tabular}




\section{Epidemiologic model equations}

$633 \frac{d N_{S 1}}{d t}=\xi N_{S 1}^{E}+f\left(1-\frac{N}{K}\right)\left(N_{S 2}+N_{S 3}+z\left(N_{E 2}+N_{E 3}\right)\right)-\left(\mu_{1}+g_{1}+\psi_{S 1} P+\xi+\beta M\right) N_{S 1}$

$634 \frac{d N_{S 2}}{d t}=\xi N_{S 2}^{E}+g_{1} N_{S 1}-\psi_{S 2} P-\left(\mu_{2}+g_{2}+\xi+\beta M\right) N_{S 2}$

$635 \frac{d N_{S 3}}{d t}=\xi N_{S 3}^{E}+g_{2} N_{S 2}-\psi_{S 3} P-\left(\mu_{3}+\xi+\beta M\right) N_{S 3}$

636

$$
\frac{\mathrm{dN}_{\mathrm{E} 1}}{d t}=\xi N_{E 1}^{E}+\beta M H N_{S 1}-\psi_{E 1} P-\left(\mu_{1}+g_{1}+\xi+\sigma\right) N_{E 1}
$$

637

$$
\frac{\mathrm{dN}_{\mathrm{E} 2}}{d t}=\xi N_{E 2}^{E}+\beta M H N_{S 2}-\psi_{E 2} P-\left(\mu_{2}+g_{2}+\xi+\sigma\right) N_{E 2}
$$

638

$$
\frac{d N_{E 3}}{d t}=\xi N_{E 3}^{E}+\beta M H N_{S 3}-\psi_{E 3} P-\left(\mu_{3}+\xi+\sigma\right) N_{E 3}
$$

$$
\frac{d N_{I 1}}{d t}=\xi N_{I 1}^{E}+\sigma N_{E 1}-\psi_{I 1} P-\left(g_{1}+\mu_{1}+\mu_{I}+\xi\right) N_{I 1}
$$

640

$$
\frac{d N_{I 2}}{d t}=\xi N_{I 2}^{E}+\sigma N_{E 2}+g_{1} N_{I 1}-\psi_{I 2} P-\left(g_{2}+\mu_{2}+\mu_{I}+\xi\right) N_{I 2}
$$

$641 \frac{d N_{I 3}}{d t}=\xi N_{I 3}^{E}+\sigma N_{E 3}+g_{2} N_{I 2}-\psi_{I 3} P-\left(\mu_{3}+\mu_{I}+\xi\right) N_{I 3}$

$642 \frac{d W_{t}}{d t}=\lambda\left(N_{I 1}+\theta_{1} N_{I 2}+\theta_{2} N_{I 3}\right)-\left(\mu_{W}+\mu_{H}\right) W_{t}$

$643 \frac{d W_{u}}{d t}=\lambda\left(N_{I 1}+\theta_{1} N_{I 2}+\theta_{2} N_{I 3}\right)-\left(\mu_{W}+\mu_{H}\right) W_{u}$

\section{MDA Implementation and DALYs estimation}

646 The model tracks treated and untreated segments of the population by dividing the

647 worm burden based on MDA coverage, such that total worm burden is a weighted average

648 of each population: $W=\operatorname{cvrg} W_{t}+(1-\operatorname{cvrg}) W_{u}$. When MDA is implemented, mean worm

649 burden in the treated compartment is reduced by $W_{t}(1-e f f)$. We assume the dispersion

650 parameter of the negative binomial distribution in each population is constant over the

651 simulation period. To estimate the total number of individuals with heavy and light egg

652 burdens, $H_{h i}$ and $H_{l o}$, respectively, we first sample $n=H * c v r g$ draws from a negative 
653 binomial distribution with mean $W_{t}$ and dispersion, $\varphi$, to represent the distribution of adult

654 worms in the treated segment of the human population. Similarly, we sample $n=H *(1-$

$655 \mathrm{cvrg}$ ) draws from a negative binomial distribution with mean $W_{u}$ and dispersion, $\varphi$, to

656 represent the distribution of adult worms in the untreated segment of the human

657 population. We then convert these individual level adult worm counts, denoted $W_{h}$, to

658 estimates of egg burden, denoted $B_{h}$, as: $B_{h}=0.5 W_{h} \phi\left(W_{h}\right) \mathcal{E}$ where $0.5 W_{h} \phi\left(W_{h}\right)$ provides

659 an estimate of the number of mated female (i.e. egg producing) worms and $\mathcal{E}$ is an estimate

660 of $S$. haematobium eggs per $10 \mathrm{~mL}$ urine per mated adult female worm from [CITE]. With the

661 full distribution of $B_{h}$, we can then estimate the number of individuals with heavy ( $>50$

662 eggs per $10 \mathrm{~mL}$ urine, $\left.H_{h i}\right)$ and light $\left(0\right.$ <eggs per $10 \mathrm{~mL}$ urine $\left.\leq 50, H_{l o}\right)$ S. haematobium

663 burdens as defined by WHO guidelines and subsequently estimate DALYs as in equation 10. 
664 Table S2: Parameters of the schistosomiasis epidemiologic model

\begin{tabular}{|c|c|c|c|c|}
\hline Parameter & $\begin{array}{l}\text { Value \& } \\
\text { Units }\end{array}$ & Description & Source & Range \\
\hline$f$ & $0.26 N_{S 1} d a y^{-1}$ & $\begin{array}{l}\text { Per-capita recruitment rate of } \\
\text { reproductive snails }\end{array}$ & 15 & {$[0.06,0.36]$} \\
\hline $\mathbf{K}$ & $50 \frac{N}{m^{2}}$ & Snail population carrying capacity & 66 & {$[25,75]$} \\
\hline$z$ & 0.5 & $\begin{array}{l}\text { Proportion of pre-patent snails that } \\
\text { reproduce }\end{array}$ & 40 & {$[0.25,1]$} \\
\hline$\mu_{1}$ & $\frac{1}{50} d a y^{-1}$ & Mortality rate of snails in size class 1 & \multirow{3}{*}{67,68} & {$[25,100]$} \\
\hline$\mu_{2}$ & $\frac{1}{75} d a y^{-1}$ & Mortality rate of snails in size class 2 & & {$[50,125]$} \\
\hline$\mu_{3}$ & $\frac{1}{100} d^{2} a y^{-1}$ & Mortality rate of snails in size class 3 & & {$[75,150]$} \\
\hline$\mu_{I}$ & $\frac{1}{10} d_{a y}{ }^{-1}$ & $\begin{array}{c}\text { Mortality rate of snails in infection } \\
\text { class I }\end{array}$ & 40 & {$[7,20]$} \\
\hline$\xi$ & $\frac{1}{5}$ year $^{-1}$ & Migration rate of snails & 69 & {$[0,1]$} \\
\hline$g_{1}$ & $\frac{1}{37} d a y^{-1}$ & Growth rate of snails in size class 1 & \multirow{2}{*}{70} & {$[20,60]$} \\
\hline$g_{2}$ & $\frac{1}{62} d a y^{-1}$ & Growth rate of snails in size class 2 & & {$[40,100]$} \\
\hline $\boldsymbol{\sigma}$ & $\frac{1}{50} d a y^{-1}$ & $\begin{array}{l}\text { Pre-patent period; transition rate of } \\
\text { snails in infection class } E \text { to infection } \\
\text { class } I\end{array}$ & 71 & {$[30,70]$} \\
\hline $\boldsymbol{m}^{\dagger}$ & 0.8 & $\begin{array}{l}\text { Infectious miracidia produced per } \\
\text { mated adult female worm }\end{array}$ & \multirow{3}{*}{15} & {$[0.5,1.5]$} \\
\hline $\boldsymbol{\beta}^{\dagger}$ & $4 \times 10^{-7}$ & $\begin{array}{l}\text { Pre-patent snails produced per } \\
\text { infectious miracidia }\end{array}$ & & $\begin{array}{r}{\left[2.0 \times 10^{-7}\right.} \\
\left.8 \times 10^{-7}\right]\end{array}$ \\
\hline$\lambda^{\dagger}$ & $7.5 \times 10^{-6}$ & $\begin{array}{l}\text { Adult worms produced per infectious } \\
\text { cercaria shed by infected snails }\end{array}$ & & $\begin{array}{l}{\left[5.0 \times 10^{-6}\right.} \\
\left.1.0 \times 10^{-5}\right]\end{array}$ \\
\hline$\theta_{1}$ & 1.31 & $\begin{array}{l}\text { Increased relative production of } \\
\text { infectious cercariae by snails in class } \\
N_{I 2}\end{array}$ & \multirow{2}{*}{43} & {$[1,5]$} \\
\hline $\boldsymbol{\theta}_{2}$ & 7.88 & $\begin{array}{l}\text { Increased relative production of } \\
\text { infectious cercariae by snails in class } \\
N_{I 3}\end{array}$ & & {$[2,10]$} \\
\hline$\varphi$ & 0.08 & $\begin{array}{l}\text { Clumping parameter of the negative } \\
\text { binomial distribution }\end{array}$ & 38 & {$[0.01,0.3]$} \\
\hline$\mu_{W}$ & $\frac{1}{3.3}$ year $^{-1}$ & Mortality rate of adult worms & \multirow{2}{*}{15} & {$[2,4]$} \\
\hline$\mu_{H}$ & $\frac{1}{60}$ year $^{-1}$ & $\begin{array}{l}\text { Mortality rate of humans harboring } \\
\text { adult worms }\end{array}$ & & {$[50,70]$} \\
\hline$D W_{h i}$ & 0.05 & $\begin{array}{l}\text { Disability weight associated with } \\
\text { heavy S. haematobium egg burden }\end{array}$ & 7,72 & {$[0.03,0.15]$} \\
\hline$D W_{l o}$ & 0.014 & $\begin{array}{l}\text { Disability weight associated with } \\
\text { heavy S. haematobium egg burden }\end{array}$ & 7,72 & {$[0.003,0.03]$} \\
\hline eff & 0.85 & MDA efficacy & & {$[0.75,0.95]$} \\
\hline $\operatorname{corg}$ & 0.75 & MDA coverage & & {$[0.5,0.95]$} \\
\hline $\mathcal{E}^{\dagger}$ & 3.6 & $\begin{array}{l}\text { Eggs produced per } 10 \mathrm{~mL} \text { urine per } \\
\text { mated adult female worm }\end{array}$ & 73 & {$[2,5]$} \\
\hline
\end{tabular}


bioRxiv preprint doi: https://doi.org/10.1101/465195; this version posted November 9, 2018. The copyright holder for this preprint (which was not certified by peer review) is the author/funder, who has granted bioRxiv a license to display the preprint in perpetuity. It is made available under aCC-BY-ND 4.0 International license.

666 Table S3: Parameters regulating snail predation of snails, linking the aquaculture model to the

667 epidemiologic model

\begin{tabular}{|c|c|c|c|c|}
\hline Parameter & $\begin{array}{l}\text { Value \& } \\
\text { Units }\end{array}$ & Description & Source & Range \\
\hline$a_{N}$ & 0.19 & $\begin{array}{l}\text { Allometric parameter for } \\
\text { snail shell width-weight } \\
\text { conversion }\end{array}$ & \multirow{4}{*}{13} & {$[0.1,0.3]$} \\
\hline$b_{N}$ & 2.54 & $\begin{array}{c}\text { Allometric parameter for } \\
\text { snail shell width-weight } \\
\text { conversion }\end{array}$ & & {$[2,3]$} \\
\hline$\alpha_{m}$ & 0.91 & $\begin{array}{l}\text { Parameter to estimate } \\
\text { prawn attack rate from } \\
\text { prawn-snail biomass ratio }\end{array}$ & & {$[0.5,1.5]$} \\
\hline$T_{h_{m}}$ & 0.39 & $\begin{array}{l}\text { Parameter to estimate } \\
\text { prawn handling time from } \\
\text { prawn-snail biomass ratio }\end{array}$ & & {$[0.2,0.5]$} \\
\hline$n$ & 2 & $\begin{array}{l}\text { Exponent of Holling's type } \\
\text { III functional response }\end{array}$ & 38 & {$[1.1,4]$} \\
\hline$\epsilon$ & $10 \%$ & $\begin{array}{l}\text { Prawn predation attack rate } \\
\text { penalty associated with } \\
\text { searching for prey in } \\
\text { wildlife rather than } \\
\text { laboratory conditions }\end{array}$ & $\begin{array}{l}\text { Estimated as } 10 \% \text { of } \\
\text { laboratory- } \\
\text { determined rates } \\
\text { with wide range } \\
\text { investigated in } \\
\text { sensitivity analysis }\end{array}$ & {$[1,100]$} \\
\hline
\end{tabular}

668

669 
bioRxiv preprint doi: https://doi.org/10.1101/465195; this version posted November 9, 2018. The copyright holder for this preprint (which was not certified by peer review) is the author/funder, who has granted bioRxiv a license to display the preprint in perpetuity. It is made available under aCC-BY-ND 4.0 International license.

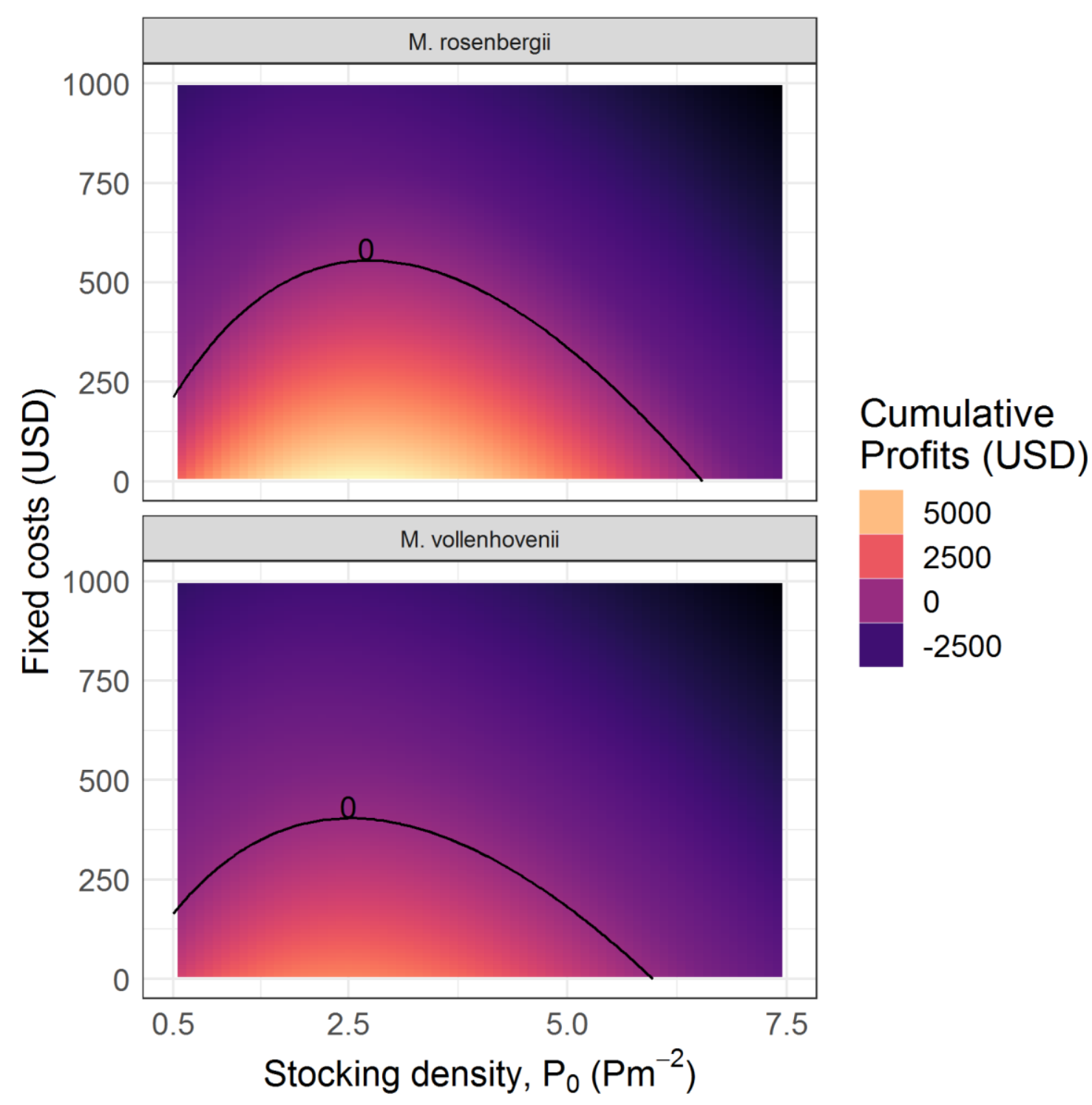

Figure S1: Sensitivity analysis investigating the influence of fixed costs incurred each aquaculture cycle on profits generated by the prawn aquaculture model. Color indicates the 10-year cumulative profits generated by optimal management with stocking at the density indicated on the $\mathrm{x}$-axis. The 675 black line delineates the maximum boundary of profitability. 
bioRxiv preprint doi: https://doi.org/10.1101/465195; this version posted November 9, 2018. The copyright holder for this preprint (which was not certified by peer review) is the author/funder, who has granted bioRxiv a license to display the preprint in perpetuity. It is made available under aCC-BY-ND 4.0 International license.

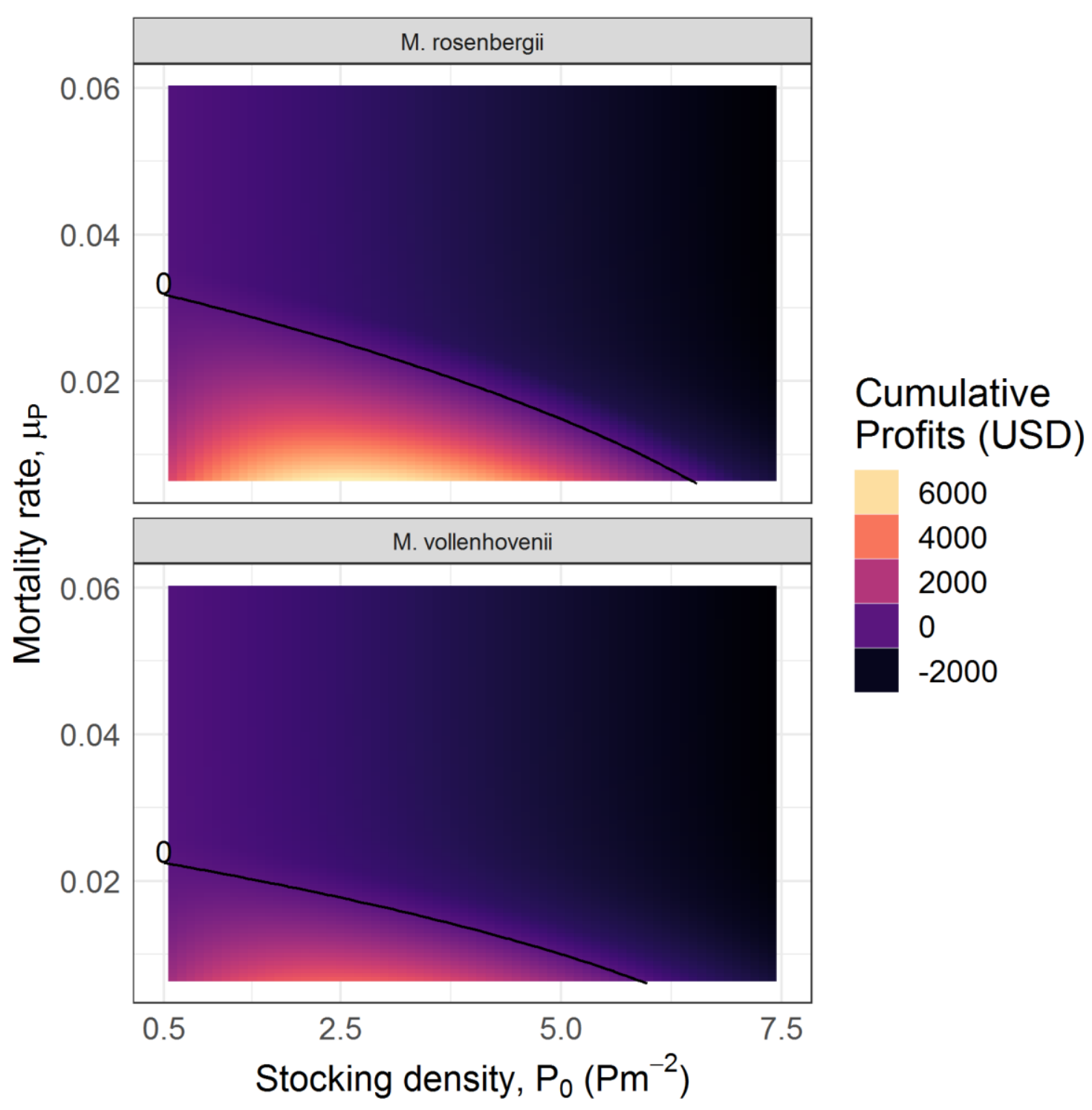

Figure S2: Sensitivity analysis investigating the influence of increased mortality rates (baseline $\mu_{P}=$ 0.006 ) on profits generated by the prawn aquaculture model. Color indicates the 10 -year cumulative profits generated by optimal management with stocking at the density indicated on the $\mathrm{x}$-axis. The black line delineates the maximum boundary of profitability. 
Holling's III, migration

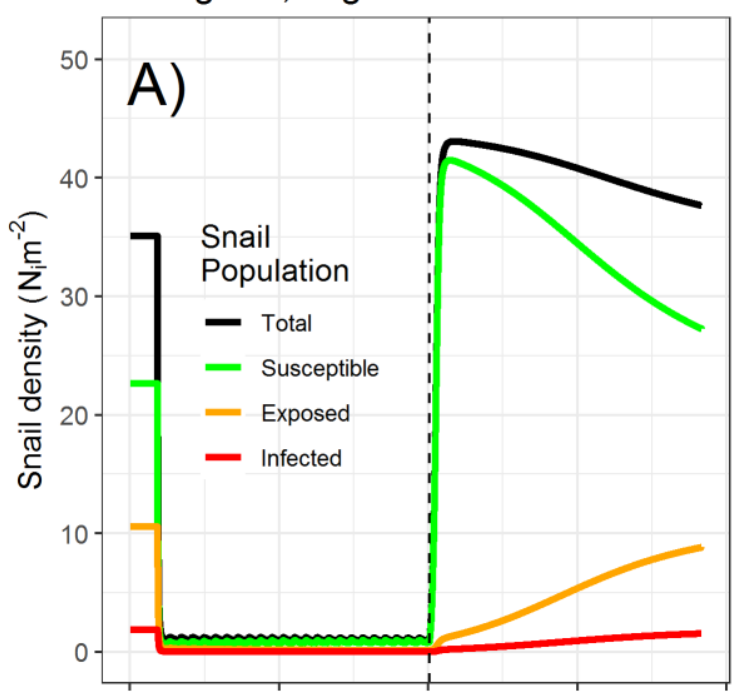

Holling's II, migration

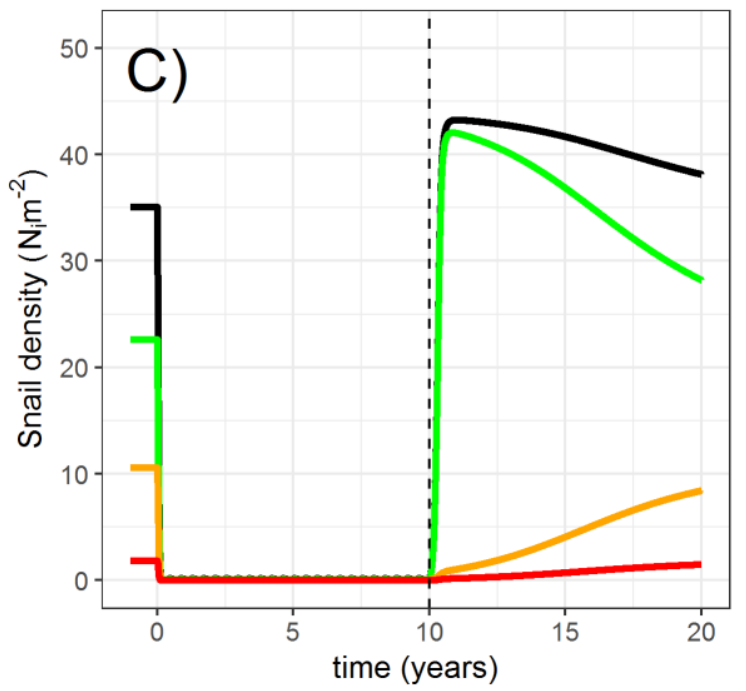

Holling's III, no migration

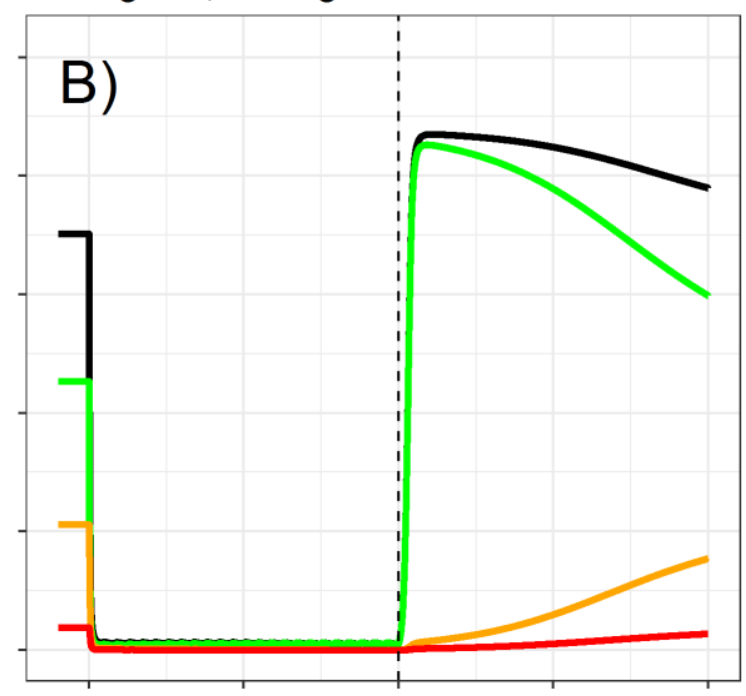

Holling's II, no migration

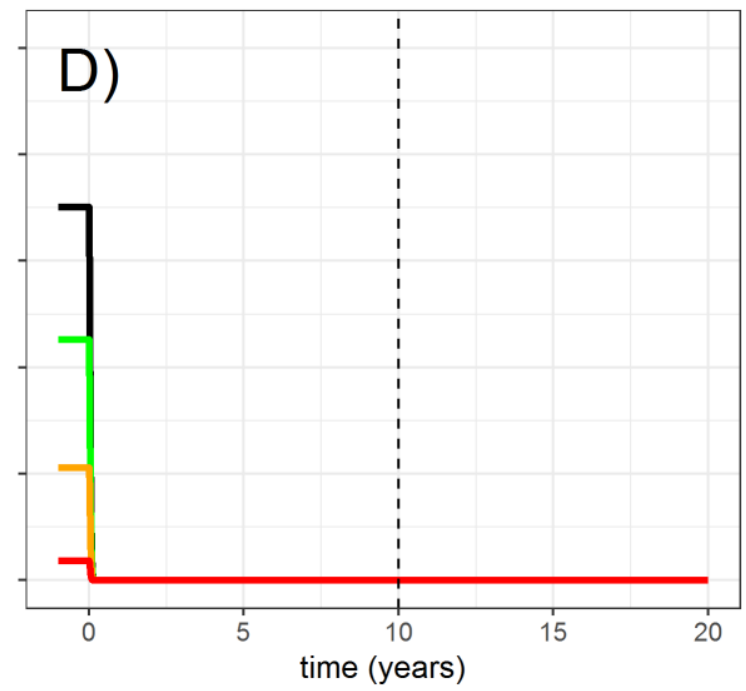

682

683

684

685

686

687

688

689

690

691
Figure S3: Sensitivity analysis investigating the influence of the predation functional response and migration on snail infection dynamics. The model is simulated assuming a type III functional response and migration from an external source (A), a type III functional response with no migration (B), a type II functional response with migration (C), and a type II functional response with no migration (D). Simulations indicate that as long as migration is present or predation dynamics follow a type III response (indicating decreased predation rates at low densities due to e.g. prey switching or the presence of prey refugia) the snail population rapidly reestablishes after prawn interventions are discontinued. 
bioRxiv preprint doi: https://doi. org/101101/465195; this version posted November 9,2018 . The copyright holder for this preprint (which was not certified by peer review) is the author/funder, who has granted bioRxiv a license to display the preprint in perpetuity. It is made available under aCC-BY-ND 4.0 International license.

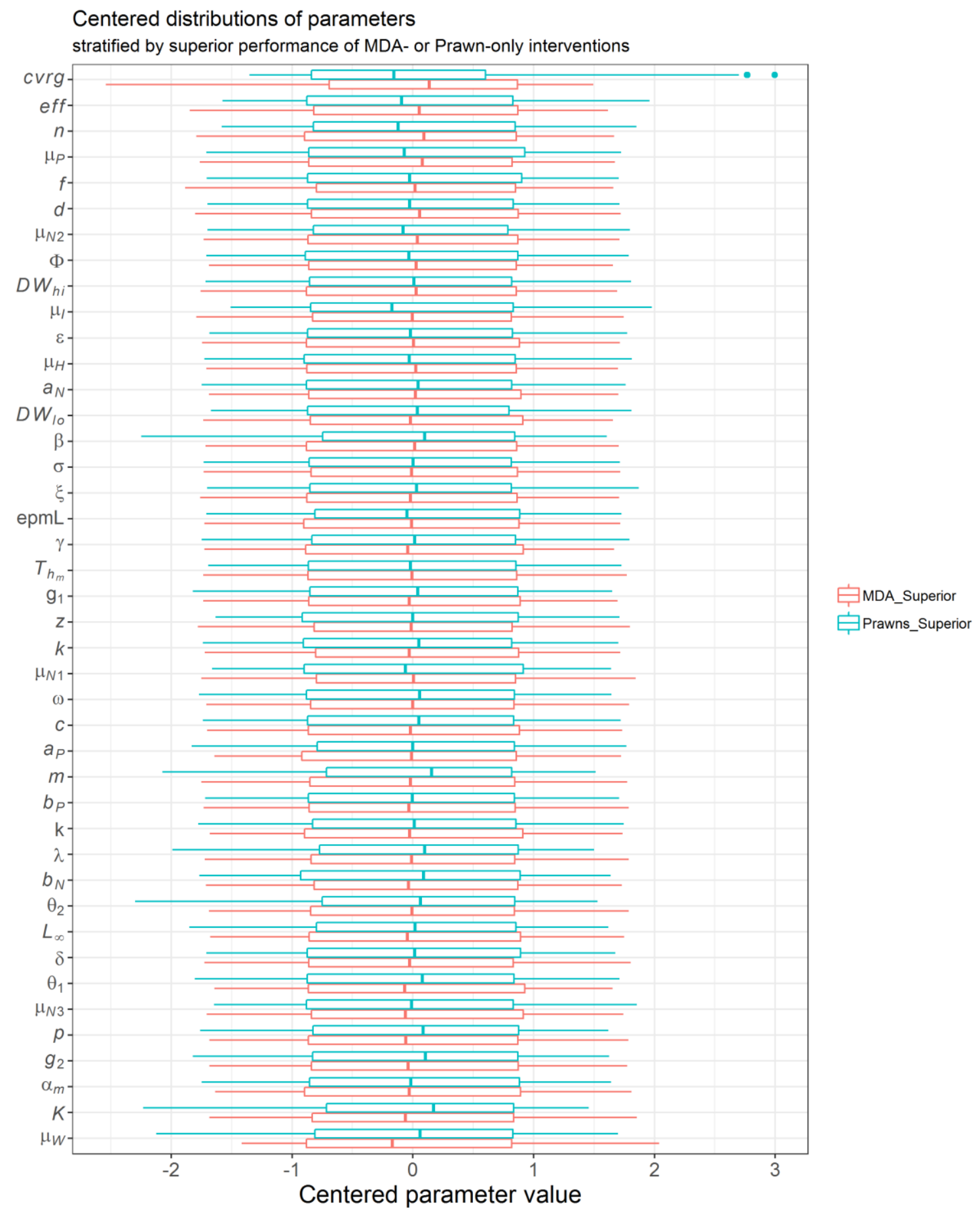

Figure S4: Centered distributions of model parameters stratified by whether more DALYs were averted in MDA-only or in Prawn-only intervention simulations compared to no intervention simulations. Comparisons show that the MDA intervention tends to perform superior when MDA coverage ( $\mathrm{cvrg}$ ) and efficacy (eff) are higher and when infected snail and prawn mortality are higher 699 $\left(\mu_{I}\right.$ and $\mu_{P}$, respectively). The prawn intervention performs notably better when the snail population carrying capacity $(K)$ is higher. 
bioRxiv preprint doi: https://doi.org/10.1101/465195; this version posted November 9, 2018. The copyright holder for this preprint (which was not certified by peer review) is the author/funder, who has granted bioRxiv a license to display the preprint in perpetuity. It is made available under aCC-BY-ND 4.0 International license.
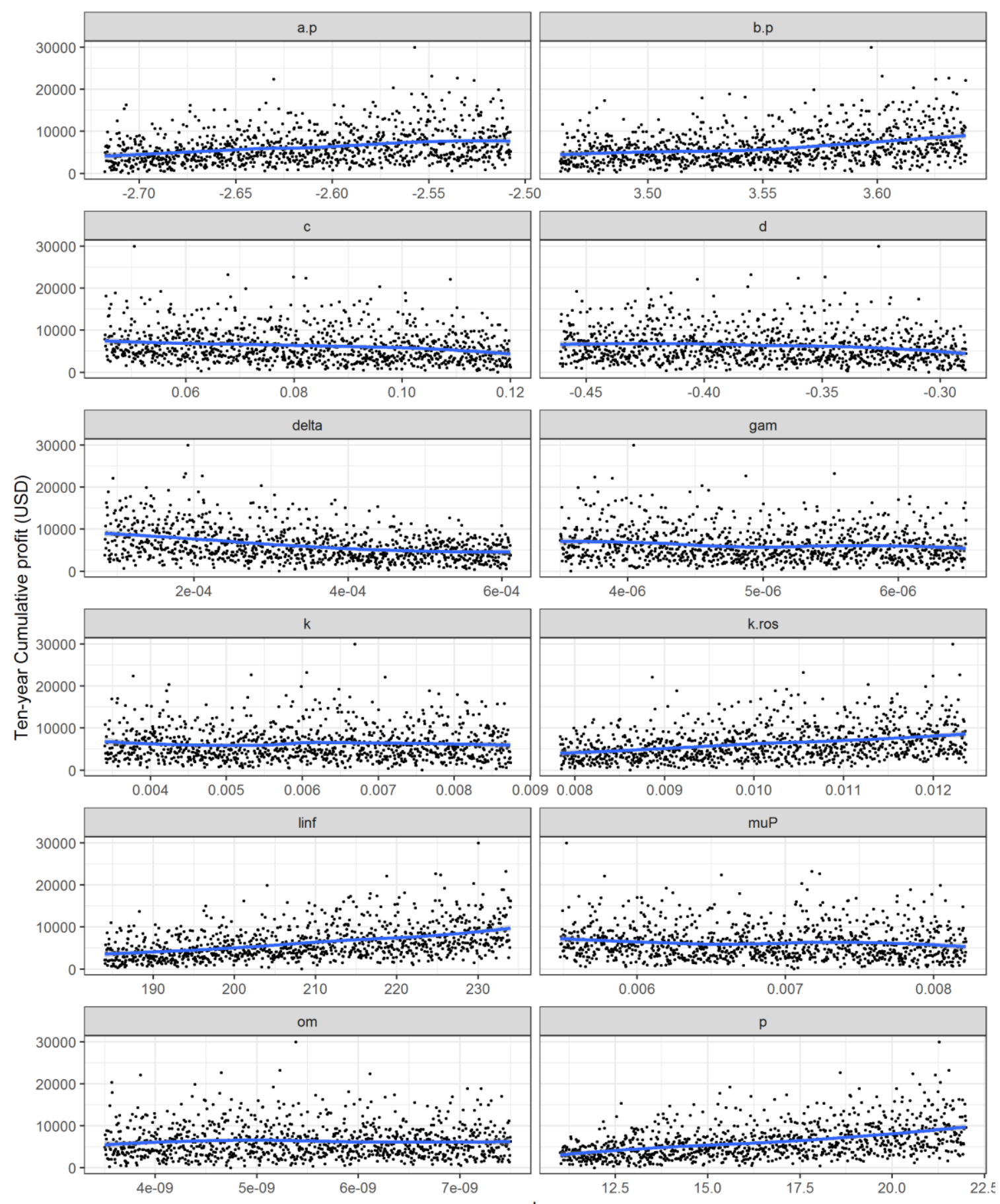

700

value

701 Figure S5: Scatterplots used to verify monotonicity between parameters of the prawn aquaculture

702 model and estimates of ten year cumulative profits. Blue lines represent loess smoothing. 
bioRxiv preprint doi: https://doi.org/10.1101/465195; this version posted November 9, 2018. The copyright holder for this preprint (which was not certified by peer review) is the author/funder, who has granted bioRxiv a license to display the preprint in perpetuity. It is made available under aCC-BY-ND 4.0 International license.

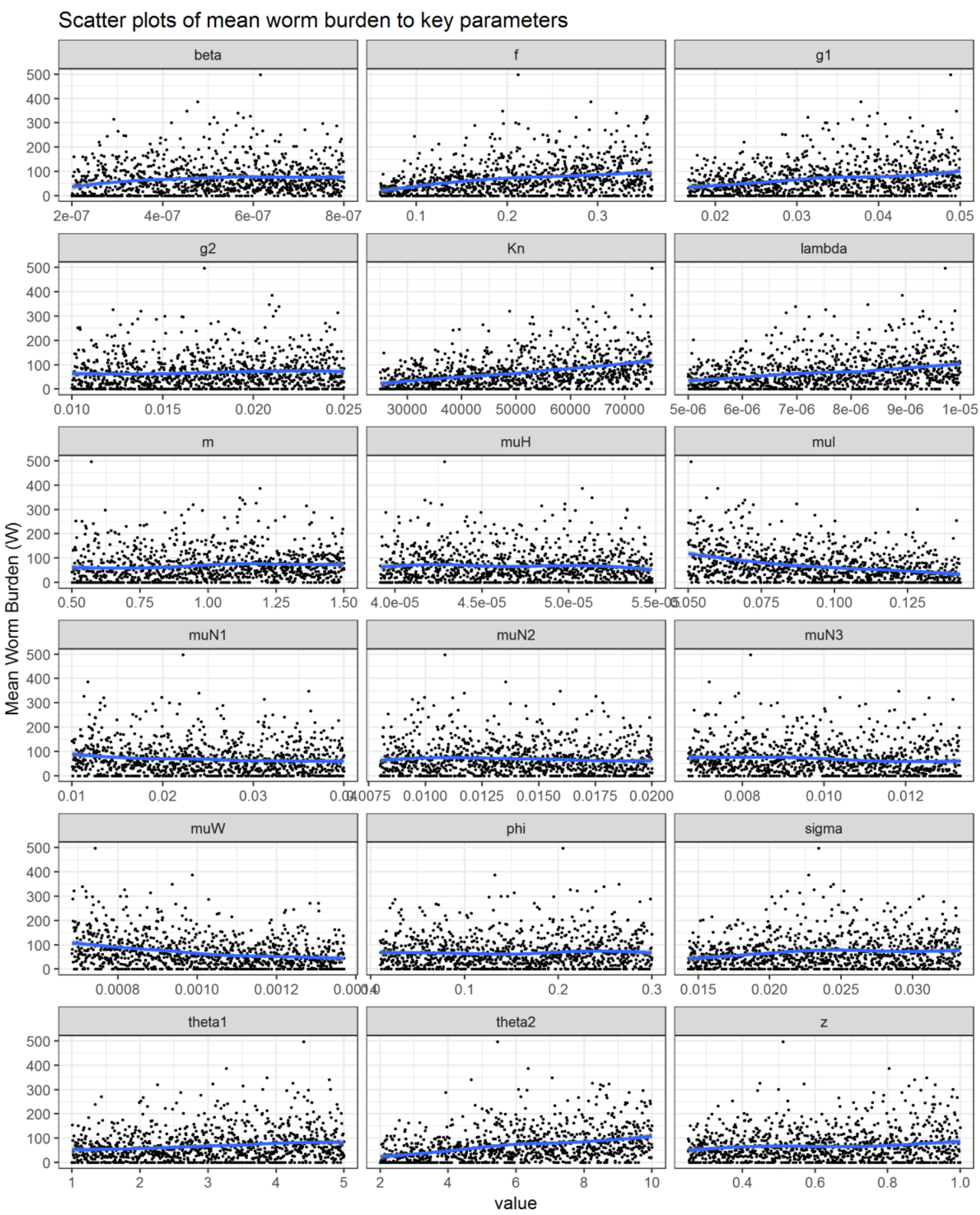

704

value

Figure S6: Scatterplots used to verify monotonicity between parameters of the epidemiologic model 
bioRxiv preprint doi: https://doi.org/10.1101/465195; this version posted November 9, 2018. The copyright holder for this preprint (which was not certified by peer review) is the author/funder, who has granted bioRxiv a license to display the preprint in perpetuity. It is made available under aCC-BY-ND 4.0 International license.

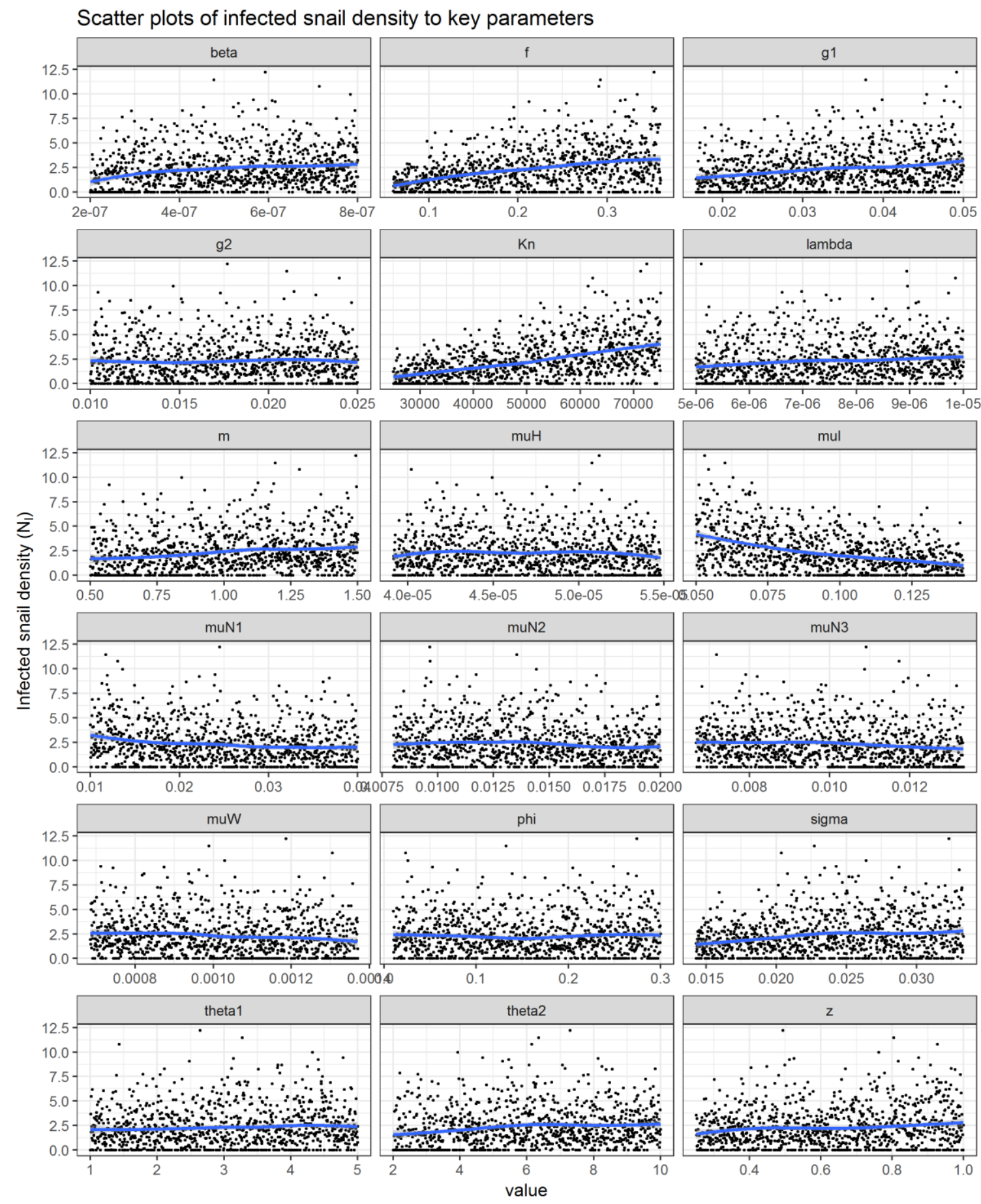

value

709 Figure S7: Scatterplots used to verify monotonicity between parameters of the epidemiologic model 710 and estimates of equilibrium infected snail density. Blue lines represent loess smoothing. 

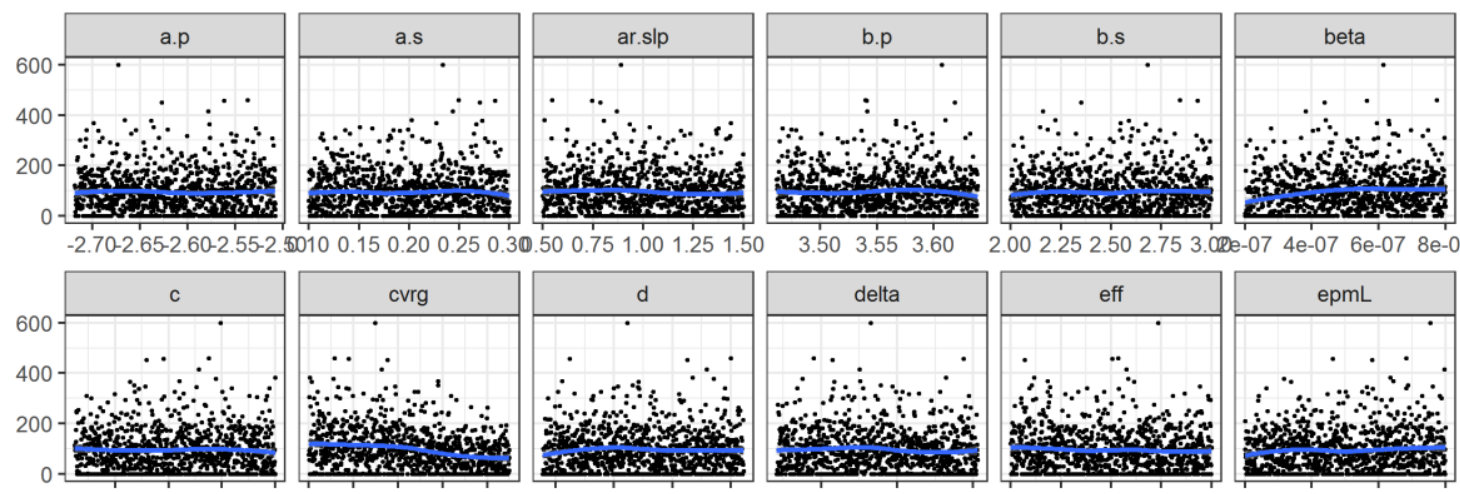

2.002 .252 .502 .75 3.00e-07 4e-07 6e-07 8e-07
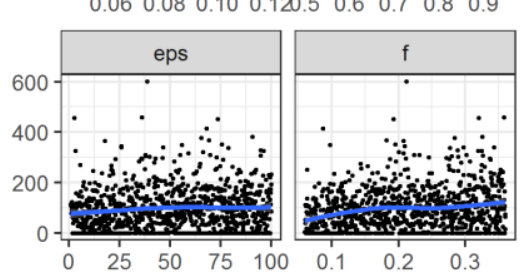

$-0.45-0.40-0.35-0.30$

$2 \mathrm{e}-04 \quad 4 \mathrm{e}-04 \quad 6 \mathrm{e}-0$
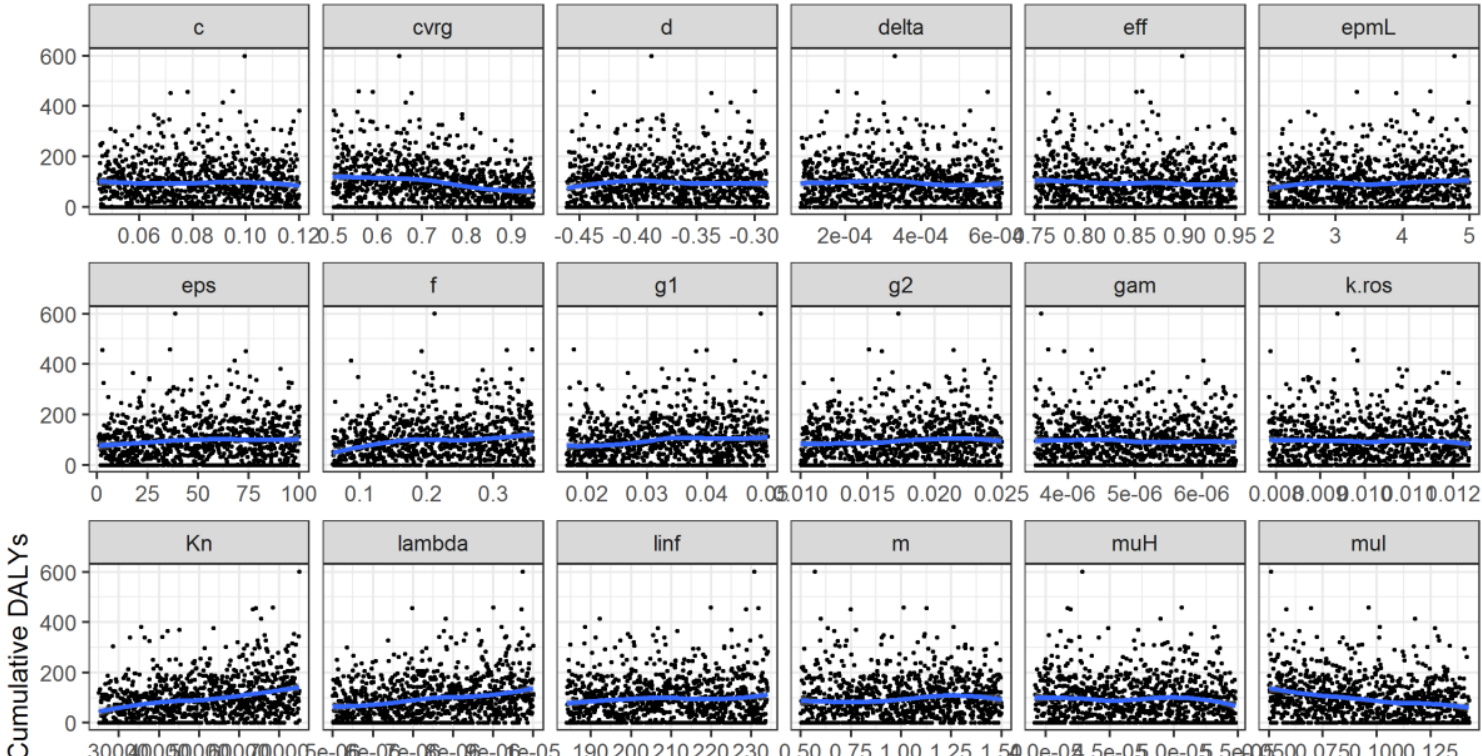

$\begin{array}{llllllll}0.02 & 0.03 & 0.04 & 0.05010 & 0.015 & 0.020 & 0.025\end{array}$

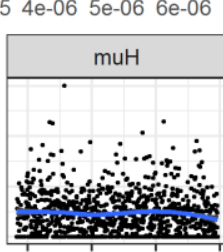

0.008 .009 .010 .010 .012
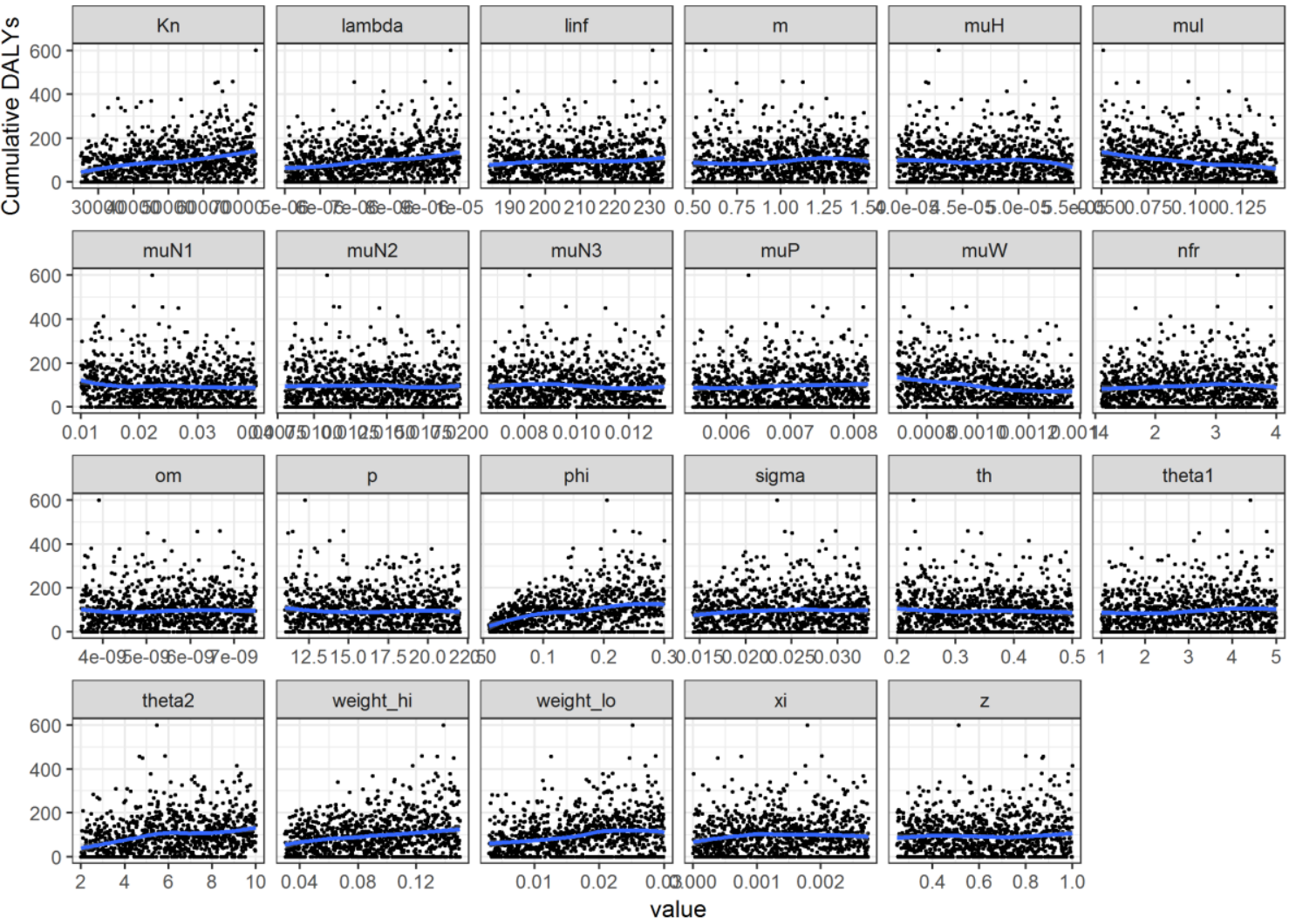

712

Figure S8: Scatterplots used to verify monotonicity between parameters of the combined model and

714

715 estimates of DALYs lost during ten years of integrated MDA and prawn intervention. Blue lines

716 represent loess smoothing. 
717

718

719

720

721

722

723

724

725

726

727

728

729

730

731

732

733

734

735

736

737

738

739

740

741

742

743

744

745

746

747

748

749

750

751

752

753

754

755

756

757

758

759

760

761

\section{References}

1. WHO. Schistosomiasis: progress report 2001-2011, strategic plan 2012-2020. (2013).

2. Lai, Y.-S. et al. Spatial distribution of schistosomiasis and treatment needs in sub-Saharan Africa: a systematic review and geostatistical analysis. Lancet. Infect. Dis. 15, 927-40 (2015).

3. Steinmann, P., Keiser, J., Bos, R., Tanner, M. \& Utzinger, J. Schistosomiasis and water resources development: systematic review, meta-analysis, and estimates of people at risk. Lancet Infect. Dis. 6, 411-425 (2006).

4. Colley, D. G. et al. Defining Persistent Hotspots: Areas That Fail to Decrease Meaningfully in Prevalence after Multiple Years of Mass Drug Administration with Praziquantel for Control of Schistosomiasis. Am. J. Trop. Med. Hyg. 97, 1810-1817 (2017).

5. Stothard, J. R. et al. Towards interruption of schistosomiasis transmission in sub-Saharan Africa: developing an appropriate environmental surveillance framework to guide and to support 'end game' interventions. Infect. Dis. Poverty 6, 10 (2017).

6. Sokolow, S. H. et al. Global Assessment of Schistosomiasis Control Over the Past Century Shows Targeting the Snail Intermediate Host Works Best. PLoS Negl. Trop. Dis. 10, e0004794 (2016).

7. Lo, N. C. et al. Impact and cost-effectiveness of snail control to achieve disease control targets for schistosomiasis. Proc. Natl. Acad. Sci. U. S. A. 115, E584E591 (2018).

8. King, C. H., Sutherland, L. J. \& Bertsch, D. Systematic Review and Meta-analysis of the Impact of Chemical-Based Mollusciciding for Control of Schistosoma mansoni and S. haematobium Transmission. PLoS Negl. Trop. Dis. 9, e0004290 (2015).

9. Andrews, P., Thyssen, J. \& Lorke, D. The biology and toxicology of molluscicides, bayluscide. Pharmacol. Ther. 19, 245-295 (1982).

10. Dawson, V. K. Environmental Fate and Effects of the Lampricide Bayluscide: a Review. J. Great Lakes Res. 29, 475-492 (2003).

11. Murray, C. J. L. et al. Disability-adjusted life years (DALYs) for 291 diseases and injuries in 21 regions, 1990-2010: a systematic analysis for the Global Burden of Disease Study 2010. Lancet 380, 2197-2223 (2012).

12. Hofkin, B. V, Hofinger, D. M., Koech, D. K. \& Loker, E. S. Predation of Biomphalaria and non-target molluscs by the crayfish Procambarus clarkii: implications for the biological control of schistosomiasis. Ann. Trop. Med. Parasitol. 86, 663-70 (1992).

13. Sokolow, S. H., Lafferty, K. D. \& Kuris, A. M. Regulation of laboratory populations of snails (Biomphalaria and Bulinus spp.) by river prawns, Macrobrachium spp. (Decapoda, Palaemonidae): implications for control of schistosomiasis. Acta Trop. 132, 64-74 (2014).

14. Mkoji, G. M. et al. Impact of the crayfish Procambarus clarkii on Schistosoma haematobium transmission in Kenya. Am. J. Trop. Med. Hyg. 61, 751-759 (1999). 
762

763

764

765

766

767

768

769

770

771

772

773

774

775

776

777

778

779

780

781

782

783

784

785

786

787

788

789

790

791

792

793

794

795

796

797

798

799

800

801

802

803

804

805

806

807
15. Sokolow, S. H. et al. Reduced transmission of human schistosomiasis after restoration of a native river prawn that preys on the snail intermediate host. Proc. Natl. Acad. Sci. U. S. A. 112, 9650-9655 (2015).

16. Roberts, J. K. \& Kuris, A. M. Predation and control of laboratory populations of the snail Biomphalaria glabrata by the freshwater prawn Macrobrachium rosenbergii. Ann. Trop. Med. Parasitol. 84, 401-12 (1990).

17. Islam, M. S. \& Wahab, M. A. A review on the present status and management of mangrove wetland habitat resources in Bangladesh with emphasis on mangrove fisheries and aquaculture. Hydrobiologia 542, 165-190 (2005).

18. Food and Agriculture Organization of the United Nations. Report of the FAO Expert Workshop on the Use of Wild Fish and/or Other Aquatic Species as Feed in Aquaculture and its Implications to Food Security and Poverty Alleviation. (Food and Agriculture Organization of the United Nations, 2008).

19. Freshwater prawns : biology and farming. (Blackwell Pub, 2010).

20. New, M. B., Valenti, W. C. \& Wiley InterScience (Online service). Freshwater prawn culture : the farming of Macrobrachium rosenbergii. (Blackwell Science, 2000).

21. Savaya Alkalay, A. et al. The Prawn Macrobrachium vollenhovenii in the Senegal River Basin: Towards Sustainable Restocking of All-Male Populations for Biological Control of Schistosomiasis. PLoS Negl. Trop. Dis. 8, e3060 (2014).

22. Levy, T. et al. All-female monosex culture in the freshwater prawn Macrobrachium rosenbergii - A comparative large-scale field study. Aquaculture 479, 857-862 (2017).

23. Hotez, P. J. et al. The Global Burden of Disease Study 2010: Interpretation and Implications for the Neglected Tropical Diseases. PLoS Negl. Trop. Dis. 8, e2865 (2014).

24. Balasubramanian, V., Sie, M., Hijmans, R. J. \& Otsuka, K. Increasing Rice Production in Sub-Saharan Africa: Challenges and Opportunities. Adv. Agron. 94, 55-133 (2007).

25. Ahmed, N. \& Garnett, S. T. Sustainability of Freshwater Prawn Farming in Rice Fields in Southwest Bangladesh. J. Sustain. Agric. 34, 659-679 (2010).

26. Ranjeet, K. \& Kurup, B. M. Heterogeneous Individual Growth of Macrobrachium rosenbergii Male Morphotypes. ICLARM Q. 25, (2002).

27. von Bertalanffy, L. A quantitative theory of organic growth (inquiries on growth laws. II). Human Biology 10, 181-213 (1938).

28. Lalrinsanga, P. L. et al. Length Weight Relationship and Condition Factor of Giant Freshwater Prawn Macrobrachium rosenbergii (De Man, 1879) Based on Developmental Stages, Culture Stages and Sex. Turkish J. Fish. Aquat. Sci. 12, 917-924 (2012).

29. Sampaio, C. M. S. \& Valenti, W. C. Growth Curves for Macrobrachium rosenbergii in Semi-Intensive Culture in Brazil. J. WORLD Aquac. Soc. 27, (1996).

30. Lima, J. de F., Garcia, J. da S. \& Silva, T. C. da. Natural diet and feeding habits of a freshwater prawn (Macrobrachium carcinus: Crustacea, Decapoda) in the estuary of the Amazon River. Acta Amaz. 44, 235-244 (2014). 
808 31. Lorenzen, K. The relationship between body weight and natural mortality in

809

810

811

812

813

814

815

816

817

818

819

820

821

822

823

824

825

826

827

828

829

830

831

832

833

834

835

836

837

838

839

840

841

842

843

844

845

846

847

848

849

850

851

852

853 juvenile and adult fish: a comparison of natural ecosystems and aquaculture. $J$. Fish Biol. 49, 627-647 (1996).

32. Nwosu, F. \& Wolfi, M. Population dynamics of the Giant African River prawn Macrobrachium vollenhovenii Herklots 1857 (Crustacea, Palaemonidae) in the Cross River Estuary, Nigeria. West African J. Appl. Ecol. 9, (2009).

33. Dasgupta, S. \& Tidwell, J. H. A Breakeven Price Analysis of Four Hypothetical Freshwater Prawn, Macrobrachium rosenbergii, Farms Using Data from Kentucky. J. Appl. Aquac. 14, 1-22 (2003).

34. Office of Management and Budget. Discount Rates for Cost-Effectiveness Analysis of Federal Programs. (2018).

35. Reed, W. J. OPTIMAL HARVESTING MODELS IN FOREST MANAGEMENT - A SURVEY. Nat. Resour. Model. 1, 55-79 (1986).

36. Karp, L., Sadeh, A. \& Griffin, W. L. Cycles in Agricultural Production: The Case of Aquaculture. Am. J. Agric. Econ. 68, 553 (1986).

37. GUTTORMSEN, A. G. Faustmann in the Sea: Optimal Rotation in Aquaculture. Marine Resource Economics 23, 401-410 (2008).

38. Halstead, N. T. et al. Agrochemicals increase risk of human schistosomiasis by supporting higher densities of intermediate hosts. Nat. Commun. 9, 837 (2018).

39. Lafferty, K. D. \& Kuris, A. M. Parasitic castration: the evolution and ecology of body snatchers. Trends Parasitol. 25, 564-572 (2009).

40. Mangal, T. D., Paterson, S. \& Fenton, A. Effects of Snail Density on Growth, Reproduction and Survival of Biomphalaria alexandrina Exposed to Schistosoma mansoni. J. Parasitol. Res. 1-6 (2010). doi:10.1155/2010/186792

41. Anderson, R. M. R. M. \& May, R. M. R. M. Infectious Diseases of Humans. (Oxford University Press, 1991).

42. May, R. M. Togetherness among Schistosomes: its effects on the dynamics of the infection. Math. Biosci. 35, 301-343 (1977).

43. Chu, K. Y. \& Dawood, I. K. Cercarial production from Biomphalaria alexandrina infected with Schistosoma mansoni. Bull. World Health Organ. 42, 569-74 (1970).

44. Holling, C. S. The Components of Predation as Revealed by a Study of SmallMammal Predation of the European Pine Sawfly. Can. Entomol. 91, 293-320 (1959).

45. Lo, N. C. et al. Assessment of global guidelines for preventive chemotherapy against schistosomiasis and soil-transmitted helminthiasis: a costeffectiveness modelling study. Lancet Infect. Dis. 16, 1065-1075 (2016).

46. Beverton, R. J. H. \& Holt, S. J. On the Dynamics of Exploited Fish Populations. (Springer Netherlands, 1993). doi:10.1007/978-94-011-2106-4

47. Zwang, J. \& Olliaro, P. L. Clinical Efficacy and Tolerability of Praziquantel for Intestinal and Urinary Schistosomiasis-A Meta-analysis of Comparative and Non-comparative Clinical Trials. PLoS Negl. Trop. Dis. 8, e3286 (2014).

48. Lo, N. C. et al. Comparison of community-wide, integrated mass drug administration strategies for schistosomiasis and soil-transmitted 
854 helminthiasis: a cost-effectiveness modelling study. Lancet Glob. Heal. 3,

855 e629-e638 (2015).

856

857

858

859

49. Soetaert, K., Petzoldt, T. \& Setzer, R. W. Solving Differential Equations in R: Package deSolve. J. Stat. Softw. 33, 1-25 (2010).

50. Marino, S., Hogue, I. B., Ray, C. J. \& Kirschner, D. E. A methodology for performing global uncertainty and sensitivity analysis in systems biology. $J$.

860

861 Theor. Biol. 254, 178-96 (2008).

862

863

864

865

866

867

868

869

870

871

872

873

874

875

876

877

878

879

880

881

882

883

884

885

886

887

888

889

890

891

892

893

894

895

896

897

898

51. Wu, J. et al. Sensitivity analysis of infectious disease models: methods, advances and their application. J. R. Soc. Interface 10, 20121018 (2013).

52. Ngonghala, C. N. et al. Poverty, Disease, and the Ecology of Complex Systems. PLoS Biol. 12, e1001827 (2014).

53. King, C. H. Parasites and poverty: The case of schistosomiasis. Acta Trop. 113, 95-104 (2010).

54. Younes, A., El-Sherief, H., Gawish, F. \& Mahmoud, M. Biological control of snail hosts transmitting schistosomiasis by the water bug, Sphaerodema urinator. Parasitol. Res. 116, 1257-1264 (2017).

55. Karplus, I. \& Sagi, A. in Freshwater Prawns 316-345 (Wiley-Blackwell). doi:10.1002/9781444314649.ch16

56. Ventura, T. \& Sagi, A. The insulin-like androgenic gland hormone in crustaceans: From a single gene silencing to a wide array of sexual manipulation-based biotechnologies. Biotechnol. Adv. 30, 1543-1550 (2012).

57. Aflalo, E. D. et al. A novel two-step procedure for mass production of all-male populations of the giant freshwater prawn Macrobrachium rosenbergii. Aquaculture 256, 468-478 (2006).

58. Levy, T. et al. A Single Injection of Hypertrophied Androgenic Gland Cells Produces All-Female Aquaculture. Mar. Biotechnol. 18, 554-563 (2016).

59. Gurarie, D., Lo, N. C., Ndeffo-Mbah, M. L., Durham, D. P. \& King, C. H. The human-snail transmission environment shapes long term schistosomiasis control outcomes: Implications for improving the accuracy of predictive modeling. PLoS Negl. Trop. Dis. 12, e0006514 (2018).

60. Civitello, D. J., Fatima, H., Johnson, L. R., Nisbet, R. M. \& Rohr, J. R. Bioenergetic theory predicts infection dynamics of human schistosomes in intermediate host snails across ecological gradients. Ecol. Lett. 21, 692-701 (2018).

61. Perez-Saez, J. et al. A Theoretical Analysis of the Geography of Schistosomiasis in Burkina Faso Highlights the Roles of Human Mobility and Water Resources Development in Disease Transmission. PLoS Negl. Trop. Dis. 9, e0004127 (2015).

62. Perez-Saez, J. et al. Hydrology and density feedbacks control the ecology of intermediate hosts of schistosomiasis across habitats in seasonal climates. Proc. Natl. Acad. Sci. 113, 6427-6432 (2016).

63. Etim, L. \& Sankare, Y. Growth and mortality, recruitment and yield of the fresh-water shrimp, Macrobrachium völlenhovenii, Herklots 1851 (Crustacea, Palaemonidae) in the Fahe reservoir, Côte d'Ivoire, West Africa. Fish. Res. 38, 211-223 (1998).

899

64. Dasgupta, S. Economics of freshwater prawn farming in the United States. South. Reg. Aquac. Cent. Nov, 1-8 (2005). 
900 65. Tidwell, J. H., D’Abramo, L. R., Coyle, S. D. \& Yasharian, D. Overview of recent

901

902

903

904

905

906

907

908

909

910

911

912

913

914

915

916

917

918

919

920

921

922

923

924

925

926

927

928

929

930 research and development in temperate culture of the freshwater prawn (Macrobrachium rosenbergii De Man) in the South Central United States. Aquac. Res. 36, 264-277 (2005).

66. Woolhouse, M. E. J. \& Chandiwana, S. K. Population biology of the freshwater snail Bulinus globosus in the Zimbabwe highveld. J. Appl. Ecol. 27, 41-59 (1990).

67. Woolhouse, M. E. J. \& Chandiwana, S. K. Population Biology of the Freshwater Snail Bulinus globosus in the Zimbabwe Highveld. J. Appl. Ecol. 27, 41 (1990).

68. McCreesh, N. \& Booth, M. The Effect of Increasing Water Temperatures on Schistosoma mansoni Transmission and Biomphalaria pfeifferi Population Dynamics: An Agent-Based Modelling Study (vol 9, e101462, 2014). PLoS One 9, (2014).

69. Head, J. R. et al. Genetic Evidence of Contemporary Dispersal of the Intermediate Snail Host of Schistosoma japonicum: Movement of an NTD Host Is Facilitated by Land Use and Landscape Connectivity. PLoS Negl. Trop. Dis. 10, e0005151 (2016).

70. McCreesh, N., Arinaitwe, M., Arineitwe, W., Tukahebwa, E. M. \& Booth, M. Effect of water temperature and population density on the population dynamics of Schistosoma mansoni intermediate host snails. Parasit. Vectors 7, 9 (2014).

71. Pflüger, W., Roushdy, M. Z. \& El Emam, M. The prepatent period and cercarial production of Schistosoma haematobium in Bulinus truncatus (Egyptian field strains) at different constant temperatures. Zeitschrift für Parasitenkd. (Berlin, Ger. 70, 95-103 (1984).

72. King, C. H., Dickman, K. \& Tisch, D. J. Reassessment of the cost of chronic helmintic infection: a meta-analysis of disability-related outcomes in endemic schistosomiasis. Lancet 365, 1561-1569 (2005).

73. Cheever, A. W. A quantitative post-mortem study of schistosomiasis mansoni in man. Am. J. Trop. Med. Hyg. 17, (1977). 